\title{
On the role of Hoogsteen:Hoogsteen interactions in RNA: Ab initio investigations of structures and energies
}

\author{
PURSHOTAM SHARMA, MOHIT CHAWLA, SITANSH SHARMA, and ABHIJIT MITRA \\ Center for Computational Natural Sciences and Bioinformatics (CCNSB), International Institute of Information Technology (IIIT-H), Gachibowli, \\ Hyderabad 500032, India
}

\begin{abstract}
We use a combination of database analysis and quantum chemical studies to investigate the role of cis and trans Hoogsteen:Hoogsteen $(\mathrm{H}: \mathrm{H})$ base pairs and associated higher-order structures in RNA. We add three new examples to the list of previously identified base-pair combinations belonging to these families and, in addition to contextual classification and characterization of their structural and energetic features, we compare their interbase interaction energies and propensities toward participation in triplets and quartets. We find that some base pairs, which are nonplanar in their isolated minimum energy geometries, attain planarity and stability upon triplet formation. A:A $\mathrm{H}: \mathrm{H}$ trans is the most frequent $\mathrm{H}: \mathrm{H}$ combination in RNA structures. This base pair occurs at many distinct positions in known rRNA structures, where it helps in the interaction of ribosomal domains in the $50 \mathrm{~S}$ subunit. It is also present as a part of tertiary interaction in tRNA structures. Although quantum chemical studies suggest an intrinsically nonplanar geometry for this base pair in isolated form, it has the tendency to attain planar geometry in RNA crystal structures by forming higher-order tertiary interactions or in the presence of additional basephosphate interactions. The tendency of this base pair to form such additional interactions may be helpful in bringing together different segments of RNA, thus making it suitable for the role of facilitator for RNA folding. This also explains the high occurrence frequency of this base pair among all $\mathrm{H}: \mathrm{H}$ interactions.
\end{abstract}

Keywords: Hoogsteen; RNA base pairing; gas phase optimizations; quartets; tRNA

\section{INTRODUCTION}

Recent mechanistic investigations into the functioning of several RNA enzymes, including the ribosome, have highlighted the need to deepen our understanding of structural principles operative in these molecules (Serganov et al. 2005; Steitz and Moore 2003; Brackett and Dieckmann 2006; Leclerc and Karplus 2006; Rodnina et al. 2006; Cochrane and Storbel 2008). Noncovalent interactions involved in the folding of the highly flexible and negatively charged sugarphosphate backbone of RNA molecules are far less understood, compared with those involved in protein folding (Černý and Hobza 2007). These interactions are also relatively more complex than in regular DNA double helices, which are held together by canonical A:T and G:C WatsonCrick (WC) base pairs that are intrinsically suited for the structure and function of DNA (Srinivasan et al. 2009). In

Reprint requests to: Abhijit Mitra, Center for Computational Natural Sciences and Bioinformatics (CCNSB), International Institute of Information Technology (IIIT-H), Gachibowli, Hyderabad 500032, India; e-mail: abi_chem@iiit.ac.in, fax: 91-40-66531413.

Article published online ahead of print. Article and publication date are at http://www.rnajournal.org/cgi/doi/10.1261/rna.1919010. keeping with their variety of functional roles, single-stranded RNA (ssRNA) molecules display far richer variation in basepairing types and geometries, which govern their "folding on themselves" into complex dynamic structures.

Noncanonical base pairs, which constitute $\sim 40 \%$ of the base-pairing interactions in RNA (Leontis and Westhof 2001), have been recognized for their role in molecular recognition events involving proteins, ligands, and metal ions. Apart from mediating numerous tertiary interactions involving loops and bulges, leading to the formation of RNA-RNA recognition motifs (Westhof and Fritsch 2000), noncanonical base pairs also play an important role in modulating the structure of A-form helical stems. These stems, when comprised of canonical A:U and G:C pairs, have the discriminatory edges of the base pairs buried deep in the major groove and are consequently rendered incapable of ligand recognition. Noncanonical base pairs have been shown to help functional RNA molecules remedy this problem in several ways. The presence of noncanonical base pairs, which are nonisosteric with canonical base pairs (Leontis et al. 2002), can distort the grooves, while those pairing through other than WC edges expose the polar groups of WC edges for molecular recognition events (Hermann and Westhof 1999). 
The significance of noncanonical base pairs is not necessarily limited to their role in shaping the RNA threedimensional (3D) structures in their static context. Recent studies, on the mechanism of aminoacylation of tRNA (McClain 2006), of the dynamics at the peptidyl transfer center of the ribosome (Korostelev et al. 2006) in the communication between the aptamer domain and the expression platform in riboswitches (Sharma et al. 2009a,b) and the like, have also highlighted the potential for their involvement in the dynamics of a variety of functional RNAs.

Leontis and Westhof (2001) classified the rich variety of RNA base pairs into 12 basic geometric families, based on the type of edge interaction (Watson-Crick [W] edge, Hoogsteen $[\mathrm{H}]$ edge, and sugar $[\mathrm{S}]$ edge [known as " $\mathrm{C}-\mathrm{H}$ edge" in the case of pyrimidines]) and the orientation (cis or trans) of glycosidic bonds. The subsequent evolution of a comprehensive and unambiguous classification scheme of base-pairing geometries (Lemieux and Major 2002; Leontis et al. 2002; Lescoute et al. 2005), along with the increasing availability of X-ray crystal structures of functional RNA molecules, has paved the way for automated detection and detailed contextual analysis of noncanonical base pairs in RNA. An interesting outcome of these developments is the recent bioinformatics-based analysis of sequences and structures of functional RNA molecules (Stombaugh et al. 2009), which has highlighted the differentiating nature of evolutionary pressure operative behind canonical base pairs and conserved noncanonical base pairs, respectively.

Canonical base pairs, both in dsDNA (double-stranded DNA) double helices as well as in stem regions of RNAs are possibly evolutionarily selected for their high interaction energies. Noncanonical base pairs in dynamic RNA molecules, on the other hand, appear to be chosen by nature primarily on the basis of their functional relevance. It is therefore not surprising that occurrence frequencies of noncanonical base pairs are not necessarily correlated with their respective pairing strengths (Sharma et al. 2008a). In fact, the search for the rationale behind their occurrences has given rise to functional hypotheses in several cases. For example, A-minor interactions (Nissen et al. 2001) with low interaction energies have been postulated to be potentially significant in the context of rapid ratchet motions implicit in ribosomal functioning (Noller 2005). Notable among highly conserved weak base pairs, where the functional contexts are not very clear, is the A:A W:W trans base pair. This base pair, having an interaction energy of only $-8.2 \mathrm{kcal} / \mathrm{mol}$ in its fully optimized geometry, not only possesses high occurrence frequency, but also it has also been found to occur in a variety of structural and functional contexts (Sharma et al. 2008a). While a large number of these contexts involve higher-order structures such as triplets and quartets, no unifying pattern has yet been reported.

The above discussion not only highlights the role of geometric classification and bioinformatics-based analysis of noncanonical base pairs, it also highlights the impor- tance of evaluating their energetics and stabilities in developing hypotheses regarding their functional roles. While an analysis of the X-ray crystal structure database can help us accomplish the former two tasks, such an analysis would not provide us with information on energetics. Several recent studies have used ab initio quantum chemical methods to address this gap (Šponer et al. 2005a,b,c; Oliva et al. 2006; Bhattacharyya et al. 2007; Sharma et al. 2007, 2008a,b; Roy et al. 2008; Mládek et al. 2009). Some observations relating to the current state of our understanding and open questions relating to the functional role of basepairing geometries and their energetics arising thereof are summarized below.

\section{Some general observations}

1. There is a large variation in the number and nature of noncovalent interactions mediating RNA base pairs, including weak (with $\mathrm{C}-\mathrm{H}$ as donor) H-bonds, bifurcated $\mathrm{H}$-bonds, and water/metal ion-mediated nucleobase interactions. Understanding the importance of these interactions requires their theoretical validation on a case-to-case basis (Mládek et al. 2009).

2. The nature of intermolecular interactions, especially the relative contribution of electrostatic and dispersion components of interbase binding, varies in different categories of base pairs. Base pairs involving sugar edge interactions, for example, show enhanced dispersion components compared to canonical base pairs (Šponer et al. 2005a,b,c; Mládek et al. 2009).

3. Often, due to the low resolution of many RNA crystal structures, the positions of all the atoms of base pairs cannot be determined unambiguously. Another issue is the proper positioning of the hydrogen atoms attached to sugar $\mathrm{O} 2$ ' and $\mathrm{NH} 2$ groups of bases, which renders ambiguity to their respective roles (donor or acceptor) in hydrogen bonding (Mládek et al. 2009). Nevertheless, analysis of RNA base pairs in crystal contexts has provided new insights into their conformational specificities and inherent flexibilities (Mukherjee et al. 2006; Olsen et al. 2009).

4. A large variation is observed in intrinsic stabilities/ instabilities of different RNA base pairs. Several of them undergo large deviations, from their RNA crystal structure geometries, when subjected to relaxed geometry optimization. This may be attributed to a variety of reasons:

- Due to the availability of alternate donors and acceptors, some base pairs have a tendency to exhibit multimodality within the same edge interaction. This may be particularly important for RNA dynamics (Bhattacharyya et al. 2007). For example, the availability of easily accessible substates helps in the local dynamics of the A-minor motif in regulating the shapes of kink-turns in rRNA (Rázga et al. 2005). 
- In addition to base-base interactions, base-sugar and base-phosphate interactions also contribute to the stability of nucleobase pairs in RNA (Zirbel et al. 2009). Several of the base-pair interactions are also known to be mediated by water or ions (Brandl et al. 2000; Müller 2008).

- The 2'-OH group of ribose and the variability in sugar edge geometry, because of sugar pucker and glycosidic torsion, play important roles in this context (Sharma et al. 2010). The resulting variability in base-pairing geometries within the sugar edge families has therefore been studied in detail (Šponer et al. 2005a,b,c; Mládek et al. 2009).

- Some functionally important, yet intrinsically unstable base pairs can possess conserved occurrence in RNA structures, provided some additional stabilizing factors are present in their vicinity. For example, the G15-C48 Levitt base pair from the crystal structure of tRNA ${ }^{\text {Phe }}$ is unstable in its isolated form (Oliva et al. 2006; Sharma et al. 2008a). However, it is shown to be stabilized in tRNA structures either by interaction with a magnesium ion or a post-transcriptional modification of the guanine base (Oliva et al. 2007).

\section{Open questions and the context of this study}

While the above discussion is indicative of a fair amount of progress toward understanding the larger picture behind the structure and dynamics of functional RNAs, a holistic understanding of RNA structural principles is far from complete. In order to reach the next level of generalization, essential for developing and validating hypotheses regarding how different base pairs may be playing different roles in various structural and functional contexts, we need to build on our current understanding to spearhead categorical investigations into different genres of physicochemical forces operative in shaping RNA structure and dynamics. In particular, we need to formulate and pursue larger questions such as:

1. Why are certain base-pair geometries more variable than others? What is the role of intrinsic topology of the interaction energy hypersurface and that of the availability of free polar groups that are open to intervention from environmental factors?

2. Given the large variety in the nature of hydrogen bonds involved, which of them are important for determining the driving forces for RNA folding?

3. What is the rationale behind conserved and recurring occurrence of weakly hydrogen-bonded base pairs? What is the rationale behind the surprising planarity, observed in RNA crystals, of some of these weakly bonded base pairs?

4. Why are certain base pairs frequently engaged in higherorder (triplets and quartets) structure formation? In these higher-order structures, can we identify the core component that may be nucleating the higher-order formation?

Complex and interdependent queries, such as those highlighted above, call for a thorough analysis of the role played by each of these base pairs in maintaining the structure and, at the same time, in facilitating the functional dynamics of RNA. While several such studies have been reported in recent times, apart from the studies on base pairs involving the sugar edge, which possess "variable geometries," the choice of RNA base-pair families investigated until now appears to have given priority either to highly populated families or to those having members possessing high occurrence frequencies. Thus, it may not be a matter of mere coincidence that, in spite of the presence of prominent members in the functionally important regions of tRNAs, the cis and trans $\mathrm{H}: \mathrm{H}$ families of base pairs have not received much attention. In this study, we have tried to look beyond the current understanding of the "significance" of various base-pair families and have focused on understanding the structural and energetic features of these two families where both the bases interact through their Hoogsteen $(\mathrm{C}-\mathrm{H}$ edge in the case of pyrimidines) edges with respective cis and trans orientation of glycosidic bonds.

The $\mathrm{H}$-edge of purines is relatively polar because of the presence of $\mathrm{N} 7$ as an acceptor in addition to one strong donor (N6 in adenine) or one strong acceptor (O6 in guanine). The $\mathrm{C}-\mathrm{H}$ edge of pyrimidines is less polar with only one strong donor (N4 in cytosine) or one strong acceptor (O4 in uracil). Given these combinations, the possibility of strong pairing with $\mathrm{H}: \mathrm{H}$ geometries becomes quite limited. Furthermore, especially for the cis $\mathrm{H}: \mathrm{H}$ geometries, because of the requirement of the nearness of $\mathrm{Cl}^{\prime}$ atoms of paired bases and the consequent torsional constraints, the expected occurrence frequencies seem to be very low. The scarcity of entries corresponding to the cis $\mathrm{H}: \mathrm{H}$ family, in the tabular listing by Leontis et al. (2002), thus reinforces our understanding. Even in the case of the trans $\mathrm{H}: \mathrm{H}$ family, apart from $\mathrm{A}: \mathrm{A} \mathrm{H}: \mathrm{H}$ trans, there are very few instances of more than one hydrogen bond for the paired bases in their experimental (RNA crystal structure) occurrences. This, however, cannot be the basis for ruling out the possibility of the functional significance of their occurrence. Our experience with sparsely hydrogen-bonded and hence weakly interacting base pairs in other families suggests that some of these base pairs may owe their conserved occurrence to contexts with unique functional significance. In fact, some of the base pairs of $\mathrm{H}: \mathrm{H}$ families are found in many important regions of ribosomal architecture such as the sarcin/ricin domain (Correll et al. 2003; Špačková and Šponer 2006), and are also found to be evolutionarily conserved in specific regions of tRNA structures (Oliva et al. 2006).

In order to probe into the geometrical features and the intrinsic stabilities of these base pairs, in terms of their 
molecular-level interactions, we have chosen well-established quantum chemical (QC) methods, which are considered superior to empirical force field-based methods. These studies have been augmented with database analysis of geometries and occurrence contexts involving $\mathrm{H}: \mathrm{H}$ base pairs. While several of these base pairs have been found to occur frequently in tRNA and rRNA structures, as our results show, the potential for contextual significance of several others cannot be ruled out.

\section{RESULTS AND DISCUSSION}

Of the 10 theoretically possible combinations for each of the $\mathrm{H}: \mathrm{H}$ cis and trans families, five combinations of $\mathrm{H}: \mathrm{H}$ cis and eight combinations spanning $10 \mathrm{bp}$ of $\mathrm{H}: \mathrm{H}$ trans have been found in the crystal-structure data set. These include A:A and A:U combinations of the $\mathrm{H}: \mathrm{H}$ cis family and the $\mathrm{U}: \mathrm{G}$ combination of the $\mathrm{H}: \mathrm{H}$ trans family, which have not been identified in earlier studies (Leontis et al. 2002; Stombaugh et al. 2009). Table 1 summarizes the details regarding the source PDB files of the base pairs and their corresponding occurrence frequencies (quoted from Stombaugh et al. 2009). Interaction energies for both gas as well as solvent phase optimized geometries, computed using the ab initio methods described in the Materials and Methods section, are given in Table 2. Main geometrical parameters, along with RMSD values quantifying the deviation of optimized geometries from their respective experimental geometries, are given in Table 3. The geometric variations, which are often accompanied by changes in hydrogen-bonding pattern (Fig. 1), have also been in-

TABLE 1. PDB ids and nucleobase ids of computed interactions involving $\mathrm{H}: \mathrm{H}$ base pairs

\begin{tabular}{|c|c|c|c|c|}
\hline Motif & $\begin{array}{l}\text { Occurrence } \\
\text { frequency }^{\mathrm{a}}\end{array}$ & PDB id & $\begin{array}{l}\text { Res } \\
(\AA)\end{array}$ & Interaction \\
\hline \multicolumn{5}{|l|}{$\mathrm{H}: \mathrm{H}$ cis } \\
\hline$A: A$ & - & $1 \mathrm{~N} 8 \mathrm{R}$ & 3.00 & A1978(A):A1981(A) \\
\hline$A: G$ & 2 & $1 \mathrm{~J} 2$ & 2.40 & A1742(O):G2033(O) \\
\hline$A: U$ & - & $2 \mathrm{I} 2 \mathrm{~T}$ & 3.22 & A933(B):U847(B) \\
\hline $\mathrm{G}: \mathrm{C}$ & 2 & $1 \mathrm{JJ} 2$ & 2.40 & G2494(O):C2493(O) \\
\hline $\mathrm{G}: \mathrm{G}$ & 2 & $1 \mathrm{~J} 2$ & 2.40 & G2616(O):G2617(O) \\
\hline \multicolumn{5}{|l|}{$\mathrm{H}: \mathrm{H}$ trans } \\
\hline$A: A$ & 97 & 2HOM & 2.89 & A53(A):A84(A) \\
\hline $\mathrm{A}: \mathrm{C}$ & 4 & $1 \mathrm{JJ} 2$ & 2.40 & A1875(O):C1856(O) \\
\hline $\mathrm{A}: \mathrm{G}$ & 3 & 1FJG & 3.00 & A415(A):G428(A) \\
\hline $\mathrm{A}: \mathrm{U}(\mathrm{I})$ & 4 & $1 \mathrm{JJ} 2$ & 2.40 & A2902(O):U2853(O) \\
\hline $\mathrm{A}: \mathrm{U}(\mathrm{II})$ & - & $2 J 01$ & 2.80 & A917(A):U860(A) \\
\hline$C: U$ & 4 & $1 \mathrm{JJ2}$ & 2.40 & C2868(O):U2889(O) \\
\hline $\mathrm{G}: \mathrm{C}(\mathrm{I})$ & 2 & $2 A Z X$ & 2.80 & G509(C):C523(C) \\
\hline $\mathrm{G}: \mathrm{C}(\mathrm{II})$ & - & $1 \mathrm{~J} 5 \mathrm{E}$ & 3.05 & G1134(O):C1129(O) \\
\hline $\mathrm{G}: \mathrm{G}$ & 2 & $1 \mathrm{~J} / 2$ & 2.40 & $\mathrm{G} 2428(\mathrm{O}): \mathrm{G} 2462(\mathrm{O})$ \\
\hline $\mathrm{U}: \mathrm{G}$ & - & 1رJ2 & 2.40 & U2541:G2611 \\
\hline
\end{tabular}

${ }^{a}$ Occurrence frequency data were taken from Stombaugh et al. (2009). The base pairs for which occurrence frequencies are not mentioned were not detected by Stombaugh et al. (2009). dependently characterized in terms of base-pair parameters (Supplemental Table S1). In order to assess the isosteric relationships between different base pairs, their glycosidic bond distances are given in Table 4. A summary of the $\mathrm{H}: \mathrm{H}$ interactions found in tRNAs conserved at the 9:12:23 position is given in Table 5. Quantum chemical calculations on higher-order structures involving $\mathrm{H}: \mathrm{H}$ base pairs, found in RNA crystal structures, are summarized in Table 6 , and their optimized geometries are given in Figures 2 and 3.

\section{Significance of the calculated base-base geometries and interaction energies}

The crystal (or experimental) geometries represent the geometries of base pairs present in the macromolecular crystal environment. Energy minimization of the crystal geometries allows us to locate the nearest local minimum around the given geometry of the base pair in the crystal. The gas phase optimized geometries are the ideal geometries that would be obtained in the absence of any other effect, whereas the solvent phase optimized geometries mimic the more realistic polar environment. The corresponding interaction energies reflect the intrinsic stability of the base pairs, which are unperturbed in their geometries by the influence of forces derived from their respective crystallographic environments. These include the effects of ions, backbone constraints, and a variety of noncovalent interactions such as base stacking and base-base, basebackbone, and backbone-backbone interactions, which influence the RNA backbone topology. Thus the relationship between geometry and the interaction energy, as observed under different idealized conditions, is expected to help in developing insights into the interplay of the forces in the crystal environment, on the one hand, and the intrinsic stabilities of the minimum-energy geometries of the different $\mathrm{H}: \mathrm{H}$ base pairs, on the other.

It may be mentioned here that interaction energies describe the component of the binding that comes from interaction of the electronic structure of two bases, which leads to greater stabilization, compared to individual monomer bases. It may therefore be argued that since the context-dependent nonelectronic components, including entropy terms, are not included, these values cannot be directly compared with the free energies of binding. However, as discussed in the Materials and Methods section, since both solvent as well as gas phase interaction energies, $E_{\mathrm{sol}}$ and $E_{\mathrm{tot}}$, 
TABLE 2. MP2/aug-cc-pVDZ interaction energies (in kilocalories per mole) for $\mathrm{H}: \mathrm{H}$ base pairs optimized at the B3LYP/6-31G $(\mathrm{d}, \mathrm{p})$ level of theory

\begin{tabular}{lcccc}
\hline $\begin{array}{l}\text { Base } \\
\text { pair }\end{array}$ & $E_{\text {int }}$ & $E_{\text {def }}$ & $E_{\text {tot }}$ & $E_{\text {sol }}$ \\
\hline $\mathrm{H}: \mathrm{H}$ cis pairs & & & & \\
A:A & -8.7 & 2.4 & -6.3 & -0.4 \\
A:G & -8.9 & 2.2 & -6.7 & -1.4 \\
A:U & -8.2 & 1.8 & -6.4 & -2.0 \\
G:C(m) & -7.3 & 1.5 & -5.8 & -0.7 \\
G:G & - & - & - & - \\
$\mathrm{H}: \mathrm{H}$ trans pairs & & & & \\
A:A & -11.8 & 2.9 & -8.9 & -4.9 \\
A:C & -10.1 & 1.6 & -8.5 & -2.5 \\
A:G & -8.6 & 2.2 & -6.4 & -2.3 \\
A:U(I) & -7.5 & 1.6 & -5.9 & -0.7 \\
A:U(II) & -6.0 & 1.2 & -4.8 & -1.7 \\
C:U & -7.9 & 1.1 & -6.8 & -2.3 \\
G:C(I) & -10.3 & 1.8 & -8.5 & -3.1 \\
G:C(II) & -10.7 & 1.9 & -8.8 & -2.8 \\
$\mathrm{G}: \mathrm{G}(\mathrm{m})^{\mathrm{a}}$ & -7.4 & 1.9 & -5.5 & -0.8 \\
$\mathrm{U}: \mathrm{G}(\mathrm{s})^{\mathrm{c}}$ & -10.9 & $2.0^{\mathrm{d}}$ & -8.9 & -0.7 \\
\hline
\end{tabular}

$E_{\text {int }}$ stands for the BSSE corrected interaction energy; $E_{\text {def }}$ is the sum of deformation energies of individual bases; $E_{\text {tot }}$ is the sum of $E_{\text {int }}$ and $E_{\text {def }} ; E_{\text {int }}, E_{\text {def, }}$ and $E_{\text {tot }}$ were determined by carrying out single point energy calculations on the gas phase optimized geometries; and $E_{\mathrm{sol}}$ is the interaction energy in the solvent phase calculated on the solvent phase optimized geometries. All these values are expressed in kilocalories per mole.

a " $(\mathrm{m})$ " Indicates that a methyl group is used to replace the sugar atom during gas phase optimization. However, during solvent phase optimization, a hydrogen atom is used to replace the sugar atom. ${ }^{b}$ This base pair converged into a highly nonplanar partially stacked structure, which is not a relevant RNA base-pair geometry. So, the interaction energy was not calculated in this case.

" " $(\mathrm{s})$ " Indicates that the ribose sugar of uracil was retained during gas phase optimization for reasons described in Materials and Methods. Although sugar was attached to uracil during gas phase optimization, the deformation energy was calculated with respect to the model with hydrogen added at the N1 position, in place of a sugar. The main reason for this is that the ribose sugar undergoes substantial rearrangement with respect to the base upon optimization, which may bias the final interaction energy values.

have been calculated in an analogous manner, our procedure gives a fairly good assessment of the bulk solvent screening of the electrostatic contribution to the base-pairing. Accordingly, the $E_{\text {tot }}$ and $E_{\text {sol }}$ values, at least in terms of relative trends, provide the basic stability order for the individual base pairs in gas phase and solvent phase.

\section{Main features related to interaction energies of the cis and trans $\mathrm{H}: \mathrm{H}$ base-pairing families}

H:H base pairs possess lower gas phase interaction energies than those of canonical base pairs

The gas phase interaction energies $\left(E_{\text {tot }}\right)$ for all the 14 computed $\mathrm{H}: \mathrm{H}$ base pairs, in their respective fully optimized geometries, were found to lie in the range of
-5.5 to $-8.9 \mathrm{kcal} / \mathrm{mol}$. These values, although significant, were considerably lower than the corresponding values for canonical A:U WC and G:C WC pairs $(-13.6$ and $-25.4 \mathrm{kcal} / \mathrm{mol}$, respectively) (Šponer et al. 2005a). This supports the hypothesis that unlike the canonical base pairs, which are primarily involved in providing stability to the RNA 3D structures, $\mathrm{H}: \mathrm{H}$ base pairs are involved in specific interactions that are evolutionarily selected for their structural and/or functional roles. This has been elaborated below, along with specific instances.

\section{A:A trans is the most stable and the most frequently occurring base pair in the $\mathrm{H}: \mathrm{H}$ families}

All the 15 studied base pairs were found to occur at least once in the selected data set of RNA structures. Out of these, in accordance with a recent bioinformatics-based listing of occurrence frequencies (Stombaugh et al. 2009), A:A trans (unless otherwise indicated, all base-pair geometries in this study imply $\mathrm{H}: \mathrm{H}$ edge interactions) is found to be the most frequently occurring. Also, with gas as well as solvent phase interaction energy values the highest within the $\mathrm{H}: \mathrm{H}$ families and with low (Table 2) RMSD values between gas phase, solvent phase, and crystal geometries, the A:A trans base pairs appear to be intrinsically quite stable.

Solvent phase interaction energy values of different $\mathrm{H}: \mathrm{H}$ base pairs show significantly altered relative order and are much lower than those obtained from gas phase calculations

As a result of attenuation of the electrostatic component in polar solvent, the solvent phase interaction energies were found to be significantly lower than the corresponding gas phase values and ranged from -0.4 to $-4.9 \mathrm{kcal} / \mathrm{mol}$ (Table 2). It was interesting to note the significant alterations in the relative ordering of the magnitudes, within the cis and trans families, respectively. This may be attributed to the variation in the relative magnitude of the electrostatic components within the respective $E_{\text {tot }}$ values. Since these numbers depend on multiple factors, including variations in the optimized geometries between gas and solution phase, respectively, nothing may be concluded unequivocally. However, at first glance, it appears that the extent of reduction in interaction energy values in the solvent phase may have some positive correlation with the dipole moments of the corresponding complexes. Thus the least amount of reduction in energy is observed in A:A trans $(4.0 \mathrm{kcal} / \mathrm{mol})$ and A:U (II) trans $(3.1 \mathrm{kcal} / \mathrm{mol})$, both of which show the two lowermost values of dipole moments. On the other hand, by far the highest amount of reduction $(8.2 \mathrm{kcal} / \mathrm{mol})$ is observed for $\mathrm{U}: \mathrm{G}(\mathrm{s})$ trans, which also has a very high dipole moment, less only than those of the G:C pairs. 
TABLE 3. Main geometrical parameters related to interbase hydrogen-bonding in $\mathrm{H}: \mathrm{H}$ base pairs in crystal geometries, gas phase optimized geometries, and solvent phase optimized geometries

\begin{tabular}{|c|c|c|c|c|c|c|c|c|c|c|c|}
\hline \multirow[b]{2}{*}{$\begin{array}{l}\text { Base } \\
\text { pair }\end{array}$} & \multirow[b]{2}{*}{ Bond } & \multicolumn{3}{|c|}{$r(D-A)(\AA)$} & \multicolumn{2}{|c|}{$r(\mathrm{~A}-\mathrm{H})(\AA)$} & \multicolumn{2}{|c|}{$\angle \mathrm{D}-\mathrm{H}-\mathrm{A}\left({ }^{\circ}\right)$} & \multirow[b]{2}{*}{$\begin{array}{c}\mathrm{RMSD}^{\mathrm{a}} \\
(\AA)\end{array}$} & \multirow[b]{2}{*}{$\begin{array}{c}\mathrm{RMSD}^{\mathrm{b}} \\
(\AA)\end{array}$} & \multirow[b]{2}{*}{$\begin{array}{c}\mathrm{RMSD}^{\mathrm{C}} \\
(\AA)\end{array}$} \\
\hline & & Crystal & $\begin{array}{l}\text { Gas } \\
\text { phase }\end{array}$ & $\begin{array}{l}\text { Solvent } \\
\text { phase }\end{array}$ & $\begin{array}{l}\text { Gas } \\
\text { phase }\end{array}$ & $\begin{array}{c}\text { Solvent } \\
\text { phase }\end{array}$ & $\begin{array}{l}\text { Gas } \\
\text { phase }\end{array}$ & $\begin{array}{l}\text { Solvent } \\
\text { phase }\end{array}$ & & & \\
\hline \multicolumn{12}{|l|}{$\mathrm{H}: \mathrm{H}$ cis } \\
\hline \multirow[t]{2}{*}{$A: A$} & $\mathrm{~N} 6-\mathrm{H}(\mathrm{A} 1) \ldots \mathrm{N} 7(\mathrm{~A} 2)$ & 3.67 & 3.05 & 3.05 & 2.03 & 2.04 & 173.7 & 171.8 & 3.75 & 3.92 & 0.67 \\
\hline & $\mathrm{C} 8-\mathrm{H}(\mathrm{A} 2) \ldots \mathrm{N} 7(\mathrm{~A} 1)$ & 2.90 & 3.27 & 3.33 & 2.31 & 2.42 & 147.3 & 140.2 & & & \\
\hline \multirow[t]{2}{*}{$\mathrm{A}: \mathrm{G}$} & $\mathrm{N} 6-\mathrm{H}(\mathrm{A}) \ldots \mathrm{O} 6(\mathrm{G})$ & 3.11 & 3.02 & 2.93 & 2.18 & 1.94 & 139.54 & 164.33 & 4.64 & 1.91 & 4.90 \\
\hline & N6-H(A)...N7(G) & - & 3.06 & - & 2.21 & - & 140.94 & - & & & \\
\hline \multirow[t]{2}{*}{$A: U$} & $\mathrm{~N} 6-\mathrm{H}(\mathrm{A}) \ldots \mathrm{O} 4(\mathrm{U})$ & 2.41 & 3.01 & 2.92 & 2.05 & 1.95 & 157.79 & 156.92 & 2.13 & 1.88 & 0.57 \\
\hline & $\mathrm{C} 5-\mathrm{H}(\mathrm{U}) \ldots \mathrm{N} 7(\mathrm{~A})$ & 3.40 & 3.30 & 3.46 & 2.21 & 2.39 & 178.13 & 168.04 & & & \\
\hline \multirow[t]{3}{*}{$\mathrm{G}: \mathrm{C}(\mathrm{m})$} & $\mathrm{C} 6-\mathrm{H}(\mathrm{C}) \ldots \mathrm{O} 6(\mathrm{G})$ & 3.49 & 3.23 & 3.29 & 2.36 & 2.45 & 134.46 & 133.17 & 1.36 & 0.96 & 0.76 \\
\hline & $\mathrm{C} 6-\mathrm{H}(\mathrm{C}) \ldots \mathrm{N} 7(\mathrm{G})$ & 3.69 & - & 3.61 & - & 2.62 & - & 160.90 & & & \\
\hline & $\mathrm{C} 5-\mathrm{H}(\mathrm{C}) \ldots \mathrm{O} 6(\mathrm{G})$ & - & 3.51 & 3.56 & 2.99 & 3.05 & 109.68 & 109.42 & & & \\
\hline $\mathrm{G}: \mathrm{G}$ & $\mathrm{C} 8-\mathrm{H}(\mathrm{G} 1) \ldots \mathrm{O} 6(\mathrm{G} 2)$ & 3.31 & - & - & - & - & - & - & - & - & - \\
\hline \multicolumn{12}{|c|}{$\mathrm{H}: \mathrm{H}$ trans } \\
\hline \multirow[t]{2}{*}{ A:A } & $\mathrm{N} 6-\mathrm{H}(\mathrm{A} 1) \ldots \mathrm{N} 7(\mathrm{~A} 2)$ & 2.70 & 3.0 & 2.94 & 2.00 & 1.95 & 164.86 & 162.43 & 1.38 & 1.52 & 0.88 \\
\hline & $\mathrm{N} 6-\mathrm{H}(\mathrm{A} 2) \ldots \mathrm{N} 7(\mathrm{~A} 1)$ & 3.40 & 3.0 & 2.95 & 2.00 & 1.95 & 164.91 & 162.32 & & & \\
\hline \multirow[t]{2}{*}{$\mathrm{A}: \mathrm{C}$} & $\mathrm{N} 4-\mathrm{H}(\mathrm{C}) \ldots \mathrm{N} 7(\mathrm{~A})$ & 2.99 & 3.00 & 2.97 & 2.13 & 1.97 & 164.98 & 163.51 & 2.75 & 2.92 & 0.47 \\
\hline & $\mathrm{N} 6-\mathrm{H}(\mathrm{A}) \ldots \mathrm{N} 4(\mathrm{C})$ & - & 3.13 & 3.27 & 2.03 & 2.28 & 156.42 & 163.90 & & & \\
\hline \multirow[t]{2}{*}{$\mathrm{A}: \mathrm{G}$} & $\mathrm{N} 6-\mathrm{H}(\mathrm{A}) \ldots \mathrm{O} 6(\mathrm{G})$ & 2.61 & 3.01 & 2.93 & 2.16 & 2.01 & 139.70 & 148.94 & 4.47 & 4.13 & 0.41 \\
\hline & $\mathrm{N} 6-\mathrm{H}(\mathrm{A}) \ldots \mathrm{N} 7(\mathrm{G})$ & - & 3.10 & 3.02 & 2.25 & 2.21 & 140.27 & 135.68 & & & \\
\hline $\mathrm{A}: U(\mathrm{I})$ & $\mathrm{N} 6-\mathrm{H}(\mathrm{A}) \ldots \mathrm{O} 4(\mathrm{U})$ & 3.15 & 2.95 & 2.92 & 1.93 & 1.93 & 172.54 & 161.61 & 4.91 & 3.06 & 3.21 \\
\hline \multirow[t]{2}{*}{$\mathrm{A}: \mathrm{U}(\mathrm{II})$} & $\mathrm{C} 5-\mathrm{H}(\mathrm{U}) \ldots \mathrm{N} 7(\mathrm{~A})$ & 2.60 & 3.45 & 3.74 & 2.41 & 2.72 & 160.29 & 156.96 & 2.67 & 3.20 & 1.15 \\
\hline & $\mathrm{C} 8-\mathrm{H}(\mathrm{A}) \ldots \mathrm{N} 4(\mathrm{U})$ & 3.29 & 3.24 & 3.30 & 2.20 & 2.25 & 158.36 & 168.56 & & & \\
\hline \multirow[t]{2}{*}{$C: U$} & $\mathrm{~N} 4-\mathrm{H}(\mathrm{C}) \ldots \mathrm{O} 4(\mathrm{U})$ & 3.39 & 2.97 & 2.90 & 1.99 & 1.89 & 161.77 & 170.06 & 2.18 & 1.55 & 1.41 \\
\hline & $\mathrm{C} 5-\mathrm{H}(\mathrm{C}) \ldots \mathrm{O} 4(\mathrm{U})$ & 3.09 & 3.62 & 3.54 & 2.83 & 2.77 & 129.77 & 127.79 & & & \\
\hline \multirow[t]{2}{*}{$\mathrm{G}: \mathrm{C}(\mathrm{I})$} & $\mathrm{N} 4-\mathrm{H}(\mathrm{C}) \ldots \mathrm{N} 7(\mathrm{G})$ & 3.16 & 3.10 & 3.00 & 2.13 & 1.98 & 160.44 & 171.45 & 1.39 & 1.24 & 0.54 \\
\hline & $\mathrm{C} 5-\mathrm{H}(\mathrm{C}) \ldots \mathrm{O} 6(\mathrm{G})$ & 3.07 & 3.45 & 3.40 & 2.38 & 2.32 & 170.99 & 175.20 & & & \\
\hline \multirow[t]{3}{*}{$\mathrm{G}: \mathrm{C}(\mathrm{II})$} & $\mathrm{N} 4-\mathrm{H}(\mathrm{C}) \ldots \mathrm{N} 7(\mathrm{G})$ & 2.98 & 3.10 & - & 2.40 & - & 126.06 & - & 3.48 & 2.71 & 2.09 \\
\hline & $\mathrm{N} 4-\mathrm{H}(\mathrm{C}) \ldots \mathrm{O} 6(\mathrm{G})$ & 3.10 & 2.99 & 2.90 & 2.03 & 1.88 & 156.86 & 178.30 & & & \\
\hline & $\mathrm{C} 5-\mathrm{H}(\mathrm{C}) \ldots \mathrm{O} 6(\mathrm{G})$ & 2.85 & - & - & - & - & - & - & & & \\
\hline \multirow[t]{2}{*}{$G: G(m)$} & $\mathrm{C} 8-\mathrm{H}(\mathrm{G} 1) \ldots \mathrm{O} 6(\mathrm{G} 2)$ & 3.24 & - & 3.23 & - & 2.27 & - & 146.56 & 4.47 & 2.61 & 3.45 \\
\hline & $\mathrm{C} 8-\mathrm{H}(\mathrm{G} 1) \ldots \mathrm{N} 7(\mathrm{G} 2)$ & - & 3.51 & - & 2.43 & - & 170.40 & - & & & \\
\hline \multirow[t]{2}{*}{$\mathrm{U}: \mathrm{G}(\mathrm{s})$} & $\mathrm{C} 5-\mathrm{H}(\mathrm{U}) \ldots \mathrm{O} 6(\mathrm{G})$ & 3.13 & 3.42 & 3.28 & 2.38 & 2.19 & 161.88 & 179.46 & 2.63 & 2.47 & 1.00 \\
\hline & $\mathrm{C} 6-\mathrm{H}(\mathrm{U}) \ldots \mathrm{N} 7(\mathrm{G})$ & - & 3.46 & 3.56 & 2.47 & 2.70 & 153.08 & 136.01 & & & \\
\hline
\end{tabular}

${ }^{\mathrm{a}} \mathrm{RMSD} 1$ is the average RMSD between initial crystal geometries and gas phase optimized geometries.

${ }^{b} \mathrm{RMSD} 2$ is the average RMSD between initial crystal geometries and solvent phase optimized geometries.

${ }^{\mathrm{C}} \mathrm{RMSD} 3$ is the average RMSD between gas phase and solvent phase optimized geometries.

\section{Classification of $\mathrm{H}: \mathrm{H}$ base pairs in terms of structurally and functionally relevant subfamilies}

The evolution of the concept of isostericity and its role in facilitating structural and functional annotation of RNA base pairs

As in the case of proteins, structures of functional RNA molecules are more conserved than their sequences. This is also true for several classes of recurrent structural building blocks or motifs, such as kink-turns (Klein et al. 2001). The variation in the sequences of these structural motifs, some of which are found to be present in widely different contexts in different RNA molecules, can even be represented using (fuzzy) regular expressions. It is however, important to understand the logic behind the allowed sequence variations within these motifs. In this context, the concept of isostericity (Leontis et al. 2002), associated with the principle of covariation, has emerged as an important tool. Thus, the so-called isostericity matrices and isodiscrepancy indices (Stombaugh et al. 2009), based on $\mathrm{Cl}^{\prime}-\mathrm{Cl}^{\prime}$ distances of the paired bases, along with some other geometrical parameters, have been used to classify base pairs within particular families into groups of base pairs that can substitute each other in sequences while maintaining the local 3D topology of RNA structures. The strong correlation between the principles of covariation with the concept of isostericity has not only been demonstrated in several studies (Leontis and Westhof 2003; Lescoute et al. 2005; Zhong et al. 2006), but this correlation has been extensively exploited in designing tools for structural and functional annotation (Yang et al. 2003) such as Ribostral (Mokdad and Leontis 2006), ISFOLD (Mokdad and Frenkel 2008), and so on. 


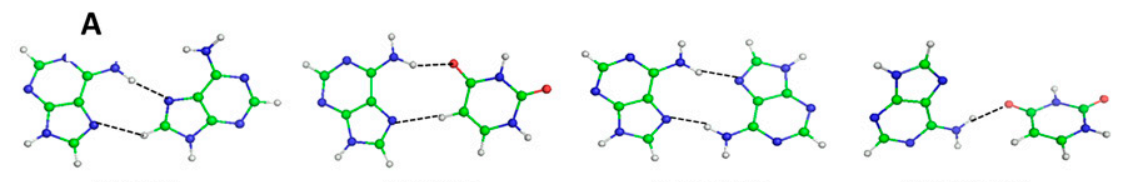

A:A H:H cis A: U H:H cis A:A H:H trans

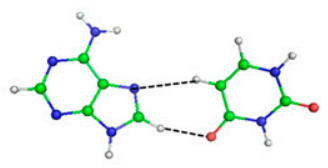

$A: U(I) H: H$ trans

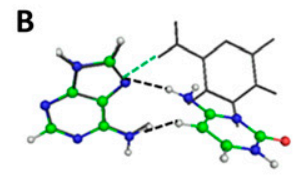

A:C H:H trans



C:U H:H trans

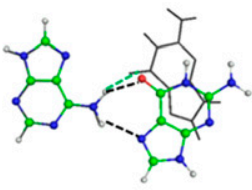

$\mathrm{A}: \mathrm{G} \mathrm{H}: \mathrm{H}$ trans

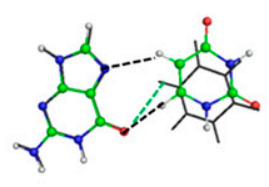

$\mathrm{U}: \mathrm{G} H: \mathrm{H}$ trans



A: G H:H cis

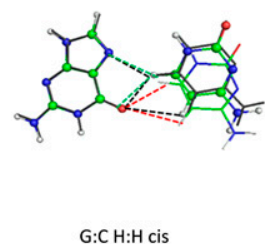

$\mathrm{G}: \mathrm{CH}: \mathrm{H}$ cis

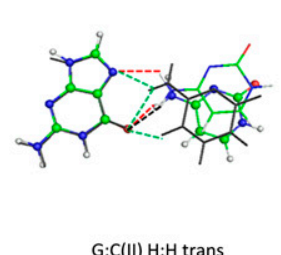

$G: C(I I) H: H$ trans

FIGURE 1. (A) Solvent phase (COSMO) optimized geometries of seven $\mathrm{H}: \mathrm{H}$ base pairs that do not show a change in $\mathrm{H}$-bonding pattern in the gas phase as well as solvent phase optimization of starting crystal geometries. (B) Superposition of solvent phase optimized geometries (ball and stick) and crystal geometries (gray sticks) of three $\mathrm{H}: \mathrm{H}$ base pairs that show a change in H-bonding pattern upon optimization of starting crystal geometries. In these cases, the $\mathrm{H}$-bonding pattern is same in the gas phase optimized as well as solvent phase optimized geometries. However, solvent phase optimized geometries are shown here by preference. $(C)$ Superposition of solvent phase optimized (ball and stick), gas phase optimized (sticks), and crystal geometries (gray sticks) of four $\mathrm{H}: \mathrm{H}$ base pairs, which show a change in $\mathrm{H}$-bonding pattern upon optimization of starting crystal geometries. In these cases, the H-bonding pattern observed in gas phase optimized geometries is different from the pattern observed in solvent phase optimized geometries. (Green) The H-bonds present in the macromolecular crystal contexts of these base pairs; (red) H-bonds observed upon gas phase optimization; (black) H-bonds observed upon solvent phase optimization. Note that hydrogen added models of crystal geometries are shown in this figure. Also, for clarity, methyl groups or sugar atoms present in some of the models of optimized geometries are replaced by hydrogen atoms.

Some issues related to the unambiguous assignment of isosteric subfamilies to $\mathrm{H}: \mathrm{H}$ base pairs

It must, however, also be remembered that isostericity does not always imply covariation. The classic case is that of the self-isosteric pairs A:G and G:A W:W cis. Despite their isostericity, they have been found not to covary whenever they occur in any functional context (Šponer et al. 2003). In most such instances, the involvement of N2 of guanine in $\mathrm{N}-\mathrm{H} . . \pi$ interaction with a stacked base above the A:G pair disrupts the $5^{\prime}$ to $3^{\prime}$ symmetry. Similarly, base pairs possessing two different substates within the same edge interaction (e.g., $\mathrm{U}: \mathrm{U} \mathrm{W}: \mathrm{W}$ trans) have different $\mathrm{C} 1^{\prime}-\mathrm{C} 1^{\prime}$ distances and do not necessarily belong to the same isosteric
$A: U(I) H: H$ trans

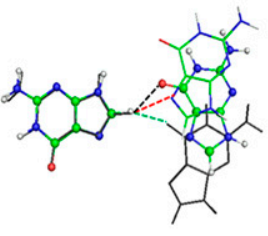

G:G H:H trans subfamily (Sharma et al. 2008a). Our studies with $\mathrm{H}: \mathrm{H}$ base pairs also brought up issues that highlight the possible lack of correlations between isostericity assignment and covariation potential.

In order to assess the covariation potentials of isosteric $\mathrm{H}: \mathrm{H}$ base pairs, we have examined the variations in their geometries within isostericity subfamilies. Since the sugar $\mathrm{Cl}^{\prime}$ atoms of the component bases were replaced with $\mathrm{H}$ atoms in most of our computed models, instead of $\mathrm{C1}{ }^{\prime}-\mathrm{C} 1$ ' distances (Leontis et al. 2002), we have considered the corresponding distances between the glycosidic $\mathrm{N}$ atoms (N1 of pyrimidines and N9 of purines), for validating isostericity assignments (Table 4). We found that the assignment of A:G trans, A:U trans, and C:U trans base pairs to the same isosteric subfamily $I_{2}$ (Leontis et al. 2002) was quite justified in terms of similarity of occurrence frequencies, interaction energies, and $\mathrm{N}-\mathrm{N}$ distances. However, additional issues arose in the context of assigning appropriate isosteric subfamilies to the three hitherto unreported base pairs, namely, A:A cis, A:U cis, and U:G trans, which were identified during our database analysis. Some of these issues, as listed below, suggest that the $\mathrm{H}: \mathrm{H}$ family contains several base pairs for which unambiguous assignment of isostericity may not be possible, at least not within the current definition of isostericity:

1. The glycosidic $\mathrm{N}-\mathrm{N}$ distances in most of the $\mathrm{H}: \mathrm{H}$ base pairs vary substantially from their corresponding distances in crystal structures upon optimization. This could be indicative of the presence of some strain in the crystal geometries of base pairs. This may also imply that the N-N distances (and consequently the $\mathrm{Cl}^{\prime}-\mathrm{C} 1^{\prime}$ distances) may be susceptible to significant contextual variation and thus constitute unlikely candidates for covariation.

2. $\mathrm{G}: \mathrm{C}$ cis and $\mathrm{G}: \mathrm{G}$ cis are assigned to the same subfamily $\mathrm{I}_{2}$, although $\mathrm{G}: \mathrm{G}$ cis has 50 times more occurrence frequency compared to $\mathrm{G}: \mathrm{C}$ cis. The very fact that the G:G cis pattern changes to a stacked structure upon unconstrained optimization (Fig. 3) may be suggestive of a lack of stable hydrogen-bonding. In that case, it is doubtful that it may covary with a stable G:C cis base pair with well-defined minimum energy geometry in $\mathrm{H}: \mathrm{H}$ cis fashion. An interesting hypothesis could be that 
TABLE 4. Glycosidic $\mathrm{N}-\mathrm{N}$ distances $(\AA)$ for the crystal geometries and full optimized geometries of $\mathrm{H}: \mathrm{H}$ base pairs

\begin{tabular}{lccc}
\hline $\begin{array}{l}\text { Base } \\
\text { pair }\end{array}$ & $\begin{array}{c}\text { Crystal } \\
\mathrm{N}-\mathrm{N} \text { distance } \\
(\AA)\end{array}$ & $\begin{array}{c}\text { Gas phase } \\
\mathrm{N}-\mathrm{N} \text { distance } \\
(\AA)\end{array}$ & $\begin{array}{c}\text { COSMO } \\
\mathrm{N}-\mathrm{N} \text { distance } \\
(\AA)\end{array}$ \\
\hline $\mathrm{H}: \mathrm{H}$ cis & & & \\
A:A & 6.07 & 6.63 & 6.72 \\
A:G & 9.42 & 8.65 & 10.37 \\
A:U & 7.78 & 7.53 & 7.79 \\
$\mathrm{G}: \mathrm{C}(\mathrm{m})$ & 6.16 & 6.64 & 6.20 \\
$\mathrm{G}: \mathrm{G}$ & 6.62 & - & - \\
$\mathrm{H}: \mathrm{H}$ trans & & & \\
A:A & 7.64 & 8.17 & 8.38 \\
A:C & 8.23 & 8.27 & 8.11 \\
A:G & 10.06 & 9.95 & 9.86 \\
A:U(I) & 9.54 & 6.77 & 9.09 \\
A:U(II) & 7.00 & 7.41 & 7.45 \\
$\mathrm{C}: \mathrm{U}$ & 9.39 & 8.49 & 8.82 \\
$\mathrm{G}: \mathrm{C}(\mathrm{I})$ & 8.96 & 8.91 & 8.59 \\
$\mathrm{G:C}(\mathrm{II})$ & 8.93 & 9.24 & 9.49 \\
$\mathrm{G}: \mathrm{G}(\mathrm{m})$ & 8.22 & 6.47 & 7.70 \\
$\mathrm{U}: \mathrm{G}(\mathrm{s})$ & 7.85 & 7.52 & 7.32 \\
\hline
\end{tabular}

G:G cis $\mathrm{H}: \mathrm{H}$ base pairs may be involved in dynamic regions of RNA structures and that the observed pattern represents only a transient state.

3. In terms of $\mathrm{N}-\mathrm{N}$ distance, interaction energy, and occurrence frequency, the newly detected A:A cis base pair appears to be isosterically related to $\mathrm{G}: \mathrm{C}$ cis and unrelated to its $\mathrm{I}_{2}$ partner G:G cis. This observation, in conjunction with the issues raised in the previous point, argues for the assignment of a separate subfamily for G:G cis different from that assigned to A:A and G:C cis base pairs.

4. A similar issue arises in the context of another newly detected base pair, U:G trans. On the basis of $\mathrm{N}-\mathrm{N}$ distance, it could be assigned to the same isosteric subfamily as that of A:A trans. However, with the latter being by far the highest occurring pair, the appropriateness of classifying it with the rarely occurring $\mathrm{U}: \mathrm{G}$ trans appears to be questionable.

5. One also needs to look into the subfamily assignment of the third newly detected base pair, A:U cis, for which the $\mathrm{N}-\mathrm{N}$ distance does not match with any other base pair in the $\mathrm{H}: \mathrm{H}$ cis family.

Classification of $\mathrm{H}: \mathrm{H}$ base pairs in terms of structural variability may be used to augment isostericity-based classification

During the course of optimization, the relative positions of the hydrogen-bond- ing donor and acceptor atoms undergo different degrees of change compared to those observed experimentally. For some base pairs, this amounts to only minor changes in the hydrogen-bonding distances. However, in several cases, optimization leads to substantial relative movement of the component bases, accompanied by changes in hydrogenbonding pattern as well as in base-pair geometry. Thus, the $\mathrm{H}: \mathrm{H}$ base pairs can be grouped into two broad categories, with the natural expectation of covarying base pairs being placed in the same category. Such a categorization may be used to augment isostericity-based classifications.

1. Base pairs showing no change in hydrogen-bonding pattern upon optimization: For the seven base pairs [A:A cis, A:U cis, A:A trans, A:U(I) trans, A:U(II) trans, $\mathrm{C}: \mathrm{U}$ trans, and $\mathrm{G}: \mathrm{C}(\mathrm{I})$ trans], no change is observed in $\mathrm{H}$-bonding pattern upon optimization of base-pair geometries extracted from RNA macromolecular context of these base pairs (Fig. 1A).

- On the basis of observed RMSD on optimization of crystal geometries, these base pairs can further be divided into two groups. The first group contains four base pairs [A:U cis, A:A trans, C:U trans, and $\mathrm{G}: \mathrm{C}(\mathrm{I})$ trans], for which a low RMSD is observed. In these cases, RMSDs upon gas phase optimization were $\leq 2.18 \AA$ (Table 3), and the solvent phase optimization resulted in an RMSD of $\leq 1.88 \AA$. Except for A:A trans, which is intrinsically nonplanar (propeller twisted by $-36.2^{\circ}\left[18.6^{\circ}\right.$ in the solvent phase]) and buckled by $8.2^{\circ}\left(-30.8^{\circ}\right.$ in the solvent phase), and C:U trans, having high propeller twist $\left(78.2^{\circ}\right)$, three other base pairs are sufficiently planar (Supplemental Table S1). The stagger values for all these base pairs also decrease upon optimization.
TABLE 5. Interactions involving $\mathrm{H}: \mathrm{H}$ base pairs in tRNA structures

\begin{tabular}{|c|c|c|c|c|}
\hline Interaction & Molecule & Organism & $\begin{array}{l}\text { Example } \\
\text { PDB id }\end{array}$ & Position \\
\hline A9:A23:U12 & $\mathrm{tRNA}^{\mathrm{Phe}}$ & Thermus thermophilus & $1 \mathrm{EIY}$ & D-stem \\
\hline A9:A23:U12 & $\mathrm{tRNA}^{\text {Asn }}$ & Saccharomyces cerevisae & 2TRA & D-stem \\
\hline A9:A23:U12 & tRNA $A^{\text {lle }}$ & Staphylococcus aueaus & $1 \mathrm{FFY}$ & D-stem \\
\hline$A 9: A 23: U 12$ & $\mathrm{tRNA}^{\mathrm{Thr}}$ & Escherichia coli & 1QF6 & D-stem \\
\hline $\begin{array}{l}\text { A9:A23:U12 } \\
\text { (A909:A923:U912) }\end{array}$ & tRNA $A^{\text {Asp }}$ & Escherichia coli & 1IL2 & D-stem \\
\hline $\begin{array}{l}\text { A9:A22:U12 } \\
\quad \text { (A909:A922:912) }\end{array}$ & tRNA ${ }^{\text {Val }}$ & Thermus thermophilus & $1 \mathrm{IVS}$ & D-stem \\
\hline A9:A24:U12 & tRNA ${ }^{\text {Tyr }}$ & Methanococcus jannaschii & $1 J 1 \mathrm{U}$ & D-stem \\
\hline A9:C23:G12 & tRNAPro & Thermus thermophilus & $1 \mathrm{H} 4 \mathrm{~S}$ & D-stem \\
\hline A9:U23:A12 & tRNA ${ }^{\text {Cys }}$ & Escherichia coli & $1 \mathrm{~B} 23$ & D-stem \\
\hline $\begin{array}{l}\text { C9:G23:C12 } \\
\text { (C509:G523:C512) }\end{array}$ & tRNA ${ }^{\text {Glu }}$ & Thermus thermophilus & $1 \mathrm{~N} 78$ & D-stem \\
\hline $\mathrm{G}: \mathrm{C}: \mathrm{G}$ trans & tRNA ${ }^{\operatorname{Trp}}$ & Homo sapiens & $2 \mathrm{AZX}$ & D-stem \\
\hline
\end{tabular}


TABLE 6. Source crystal structures and $\mathrm{H}: \mathrm{H}$ interaction energies in $\mathrm{B} 3 \mathrm{LYP} / 6-31 \mathrm{G}(\mathrm{d}, \mathrm{p})$ optimized geometries of higher-order structures involving $\mathrm{H}: \mathrm{H}$ base pairs

\begin{tabular}{|c|c|c|c|c|c|c|c|}
\hline $\begin{array}{l}\text { System } \\
\text { number }\end{array}$ & Motif & PDB & $\begin{array}{c}\text { Type } \\
\text { of RNA }\end{array}$ & $\begin{array}{l}\text { Res } \\
(\AA)\end{array}$ & Interaction & $\begin{array}{c}E_{\mathrm{int}}^{\mathrm{c}} \\
(\mathrm{kcal} / \mathrm{mol})\end{array}$ & $\begin{array}{c}\text { Average } \\
\text { RMSD }^{d} \\
(\AA)\end{array}$ \\
\hline 1 & $\mathrm{~A}: \mathrm{G}: \mathrm{C}$ cis & 1JJ2 & rRNA & 2.40 & A1472:G2033:C2037 & -21.3 & 4.57 \\
\hline 2 & $\mathrm{~A}: \mathrm{A}: \mathrm{A}$ trans & $2 J 01$ & rRNA & 2.80 & A371:A402:A423 & -12.1 & 0.33 \\
\hline 3 & $\mathrm{~A}: \mathrm{A}: \mathrm{G}$ trans & $1 \mathrm{JJ} 2$ & rRNA & 2.40 & A477:A463:G458 & -11.9 & 0.15 \\
\hline 4 & $\mathrm{~A}: \mathrm{A}: \mathrm{G}: \mathrm{C}$ trans & $2 \mathrm{I} 2 \mathrm{~T}$ & rRNA & 3.22 & A204:A191:G799:C678 & -11.9 & 0.13 \\
\hline 5 & $\mathrm{~A}: \mathrm{A}(\mathrm{m}): \mathrm{C}: \mathrm{G} \operatorname{trans}^{\mathrm{a}}$ & $2 \mathrm{HOJ}$ & mRNA & 2.50 & A53:A84:C50:G16 & -11.8 & 0.13 \\
\hline 6 & $\mathrm{~A}: \mathrm{U}: \mathrm{G}$ trans & $2 J 01$ & rRNA & 2.80 & A917:U860:G859 & -5.65 & 0.56 \\
\hline 7 & $\mathrm{C}: \mathrm{G}: \mathrm{C}$ trans & $2 U \cup B$ & rRNA & 2.80 & C1129:G1134:C1140 & -12.5 & 1.67 \\
\hline 8 & $\mathrm{~A}: \mathrm{A}: \mathrm{U}$ trans & $2 \mathrm{IY} 5$ & tRNA & 3.10 & A9:A23:U12 & -11.6 & 0.13 \\
\hline 9 & $\mathrm{~A}: \mathrm{C}: \mathrm{G}$ trans & $1 \mathrm{H} 4 \mathrm{~S}$ & tRNA & 2.85 & A9:C23:G12 & -11.1 & 4.52 \\
\hline 10 & $\mathrm{~A}: \mathrm{U}: \mathrm{A} \operatorname{trans}^{\mathrm{b}}$ & $1 \mathrm{~B} 23$ & tRNA & 2.60 & A9:U23:A12 & -11.4 & $3.70,6.50$ \\
\hline 11 & $\mathrm{C}: \mathrm{G}: \mathrm{C}$ trans & 2DER & tRNA & 3.10 & C9:G23:C12 & -11.5 & 2.02 \\
\hline 12 & $\mathrm{G}: \mathrm{C}: \mathrm{G}$ trans & $2 A Z X$ & tRNA & 2.80 & G509:C523:G512 & -13.0 & 0.51 \\
\hline
\end{tabular}

a" $(\mathrm{m})$ " Means methylation of adenine at N9 position to avoid donor capabilities of N9, which cannot exist in base pairs due to attachment of sugar at this position.

${ }^{\mathrm{b}}$ This triplet involved A:A H:H cis pairing as well as $\mathrm{A}: \mathrm{U}: \mathrm{H}$ trans pairing. For this triplet, both $\mathrm{A}: \mathrm{U}-\mathrm{A}: \mathrm{U}$ as well as A:A-A:A RMSDs are given in the last column.

${ }^{\mathrm{C}} E_{\mathrm{int}}$ is the energy of interaction between the least interacting out of two bases of the $\mathrm{H}: \mathrm{H}$ base pair, and the rest of the triplet structure, calculated at the MP2/aug-cc-pVDZ level.

${ }^{d}$ RMSD is calculated between the geometry of the respective $\mathrm{H}: \mathrm{H}$ trans pair in its isolated minimum energy form and its geometry in the triplet.

- The second group consists of three base pairs [A:A cis, $\mathrm{A}: \mathrm{U}(\mathrm{I})$ trans, and $\mathrm{A}: \mathrm{U}(\mathrm{II})$ trans], which show high RMSDs of $\geq 2.47 \AA$ upon gas phase optimization, and $\geq 3.06 \AA$ upon solvent phase optimization. In the case of A:A cis, energy minimization resulted in the optimization of interbase H-bonds, accompanied by a decrease in buckle and propeller twist. On the other hand, optimization of the $\mathrm{A}: \mathrm{U}(\mathrm{I})$ trans base pair leads to a geometry with high buckle and propeller, implying that this pattern, stabilized by a single N6-

$\mathrm{H}(\mathrm{A}) \ldots \mathrm{O} 4(\mathrm{U}) \mathrm{H}$-bond in the crystal structure, is intrinsically unstable. Optimization of the A:U(II) base pair also resulted in an increase in open angle. However, two H-bonds, albeit weak, help this base pair retain sufficient planarity upon optimization.

2. Base pairs showing change in hydrogen-bonding pattern upon optimization: Eight base pairs [A:G cis, $\mathrm{G}: \mathrm{C}(\mathrm{m})$ cis, G:G cis, A:C trans, A:G trans, G:C(II) trans, G:G(m) trans, and $\mathrm{U}: \mathrm{G}(\mathrm{s})$ trans] show a change in H-bonding pattern upon optimization (Fig. 1B,C).

- For two of these base pairs [A:G cis and $\mathrm{G}: \mathrm{G}(\mathrm{m})$ trans], this was observed only upon gas phase optimization and was accompanied by a large RMSD (Table 3). In A:G cis, this resulted in its migration from an experimentally observed single H-bonded pattern to a bifurcated H-bonding pattern. Interestingly, this bifurcated $\mathrm{H}$-bond pattern for $\mathrm{A}: \mathrm{G}$ cis is also observed at 909:912 positions (PDB id 2DU6) in the D-arm of tRNA. Optimization of
$\mathrm{G}: \mathrm{G}(\mathrm{m})$ trans results in the change of experimentally observed C8-H. . .O6 interaction to a C8-H. . .N7 interaction. As expected for base pairs held by a single hydrogen bond, this change is accompanied by a large increase in the open angle (Supplemental Table S1).

- In the case of $\mathrm{G}: \mathrm{C}(\mathrm{II})$, optimization resulted in the loss of a C5-H. . .O6 H-bond and a decrease in buckle by at least by $12^{\circ}$. For G:C cis, A:C trans, A:G trans, and $\mathrm{U}: \mathrm{G}(\mathrm{s})$ trans, additional $\mathrm{H}$-bonds are formed upon gas phase and/or solvent phase optimization. Thus, solvent phase optimization of G:C cis resulted in an additional weak $\mathrm{C}-\mathrm{H}$... O bond. A:C trans geometry changes to an amino-donor amino-acceptor bifurcated pattern with interaction of the N6-amino group of adenine with the N4-amino group of cytosine. For the A:G trans base pair, an additional $\mathrm{N} 6-\mathrm{H}(\mathrm{A}) \ldots \mathrm{N} 7(\mathrm{G})$ bond is formed upon optimization, resulting in a bifurcated pattern similar to A:G cis, albeit with opposite orientation of glycosidic bonds. On the other hand, G:G cis resulted in a highly nonplanar partially stacked geometry upon optimization, which is not relevant to RNA structures (not shown in Fig. 1).

\section{Tertiary and neighboring interactions involving $\mathrm{H}: \mathrm{H}$ base pairs in RNA crystal structures}

We carried out a search across our data set of RNA 3D structures to locate $\mathrm{H}: \mathrm{H}$ base-pairing interactions and to analyze their structural contexts. Our studies revealed that at least five of the $\mathrm{H}: \mathrm{H}$ base pairs participate in the 

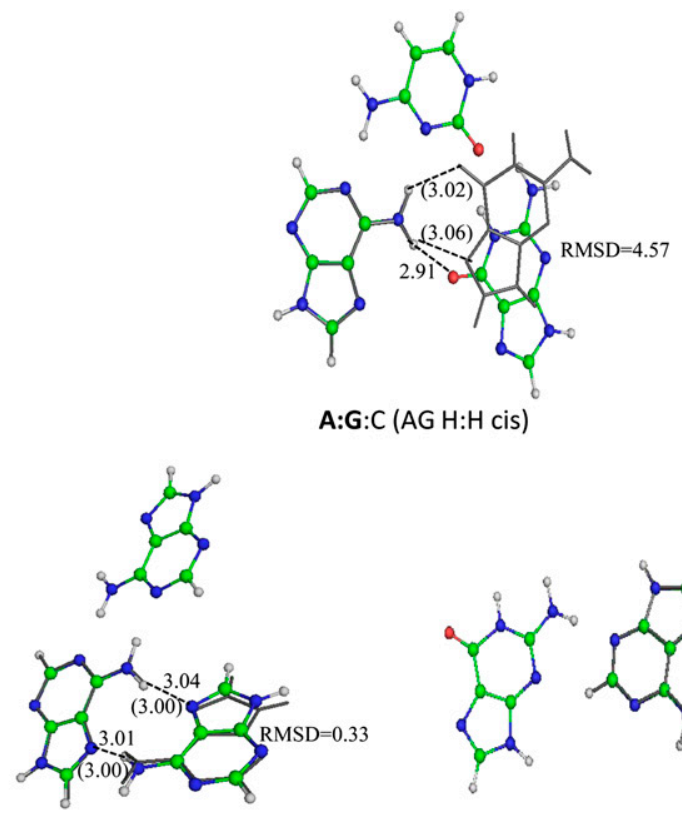

A:A:A (AA H:H trans)

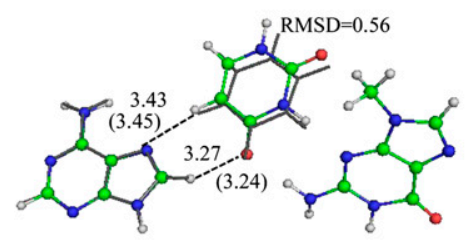

A:U:G (A:U(II) H:H trans)

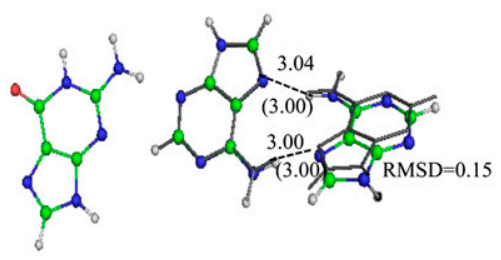

A:A:G (AA H:H trans)



C:G:C (G:C(II) H:H trans)

FIGURE 2. Superposition of $\mathrm{H}: \mathrm{H}$ base-pair geometries present in gas phase (gray sticks) and in triplets. The donor-acceptor distances in parentheses are for gas phase optimized structures, whereas the values outside the parentheses are for geometries of $\mathrm{H}: \mathrm{H}$ base pairs in triplets. Corresponding to each triplet, the $\mathrm{H}: \mathrm{H}$ base-pair combination is written in parentheses.

formation of higher-order structures, such as base triplets and quartets, some of which were found to be conserved, with substitution variations, in homologous sequences (Table 5). With higher-order structures involving A:A trans found to be most frequently occurring, triplets involving A:A and A:G from the cis family and both triplets and quartets involving A:G and G:C from the trans family have been observed in tRNA as well as rRNA structures. At least one example each of the observed triplet combinations is given in Table 6 .

The best example of conserved and covarying tertiary interactions involving $\mathrm{H}: \mathrm{H}$ trans base pairs occurs in tRNAs at positions 9 and 23 in the standard numbering for tRNAs. This pair occurs as a part of an important tertiary interaction, where one of the bases of the 12:23 canonical pair of the D-stem interacts with a third base from the D-arm at the elbow of the tRNA structure (Table 5). In the analyzed tRNAs, the pairing is either A9:A23:U12, A9:C23:G12, A9:U23:A12, C9:G23:C12, or G9:C23:G12. The principal variant A:A trans has been observed in the crystal structures of tRNA ${ }^{\text {Phe }}$, $\mathrm{tRNA}^{\text {Asn }}, \mathrm{tRNA}^{\mathrm{Ile}}, \mathrm{tRNA}^{\mathrm{Thr}}$, $\mathrm{tRNA}^{\text {Asp }}$, $\mathrm{tRNA}^{\mathrm{Val}}$, and tRNA ${ }^{\mathrm{Tyr}}$ structures (Table 5). This covariation of $\mathrm{A}: \mathrm{A}, \mathrm{A}: \mathrm{C}$, and $\mathrm{A}: \mathrm{U}$ and $\mathrm{G}: \mathrm{C}$ base-pair combinations in $\mathrm{H}: \mathrm{H}$ cis fashion in tRNA structures indicates that they can substitute for each other in homologous sequences.

A number of A:A $\mathrm{H}: \mathrm{H}$ trans basepairing interactions also occur in the 50S subunit. Some of them act as tertiary interactions between domains of the subunit, while others are present in internal loops. For example, the A52:A119 interaction occurs in 5S rRNA. The A918:A2268 H:H trans base pair is a $2 / 5$ domain tertiary interaction joining the 38 and 81 helices in the Escherichia coli $50 \mathrm{~S}$ ribosomal subunit (PDB id: 2AWB), whereas A1265:A2014 and A1427:A1571 are 3/4 domain and $2 / 3$ domain tertiary interactions (PDB id: 2I2T). Similarly, A191:A204, A241:A256, A371:A402, A477:A501, and A457:A471 occur in internal loops in various segments of the 50S subunit. A:A H:H trans interactions also occur at important positions in $30 \mathrm{~S}$ and $50 \mathrm{~S}$ ribosomal segments of other organisms. A list of observed $\mathrm{H}: \mathrm{H}$ interactions, in various PDB files, has been compiled in Supplemental Tables S2-S6.

\section{Optimal geometries of higher-order interactions involving $\mathrm{H}: \mathrm{H}$ base pairs}

In this section, we analyze the optimized geometries of base triplets and quartets involving $\mathrm{H}: \mathrm{H}$ trans base pairs identified from RNA crystal structures. Using the BPFind tool (Das et al. 2006), we were able to extract 12 distinct higher-order structures involving $\mathrm{H}: \mathrm{H}$ base pairs, which include 10 base triplets and two quartets. We observed one triplet involving an $\mathrm{H}: \mathrm{H}$ cis base pair (System 1) (Table 5), one triplet (System 10) involving an $\mathrm{H}: \mathrm{H}$ cis pair as well as an $\mathrm{H}: \mathrm{H}$ trans pair, and eight triplets (Systems 2, 3, 6-9, 11, and 12) and two quartets (Systems 4 and 5) involving $\mathrm{H}: \mathrm{H}$ trans base pairs. We carried out gas phase optimizations on all these distinct combinations in order to obtain minimum energy structures for subsequent analysis. The purpose of analyzing higher-order structures in the context of $\mathrm{H}: \mathrm{H}$ base-pairing is twofold:

1. To estimate the extent of deformation that each $\mathrm{H}: \mathrm{H}$ base pair experiences, in order to form a higher-order structure such as a triplet or quartet. 


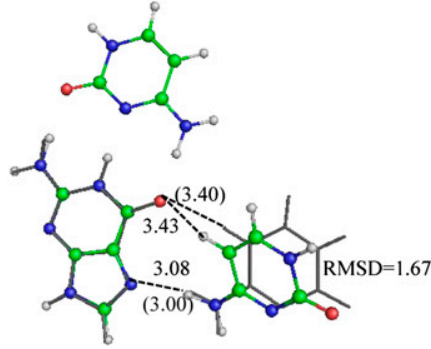

C9:G23:C12 (G:C(I) H:H trans)
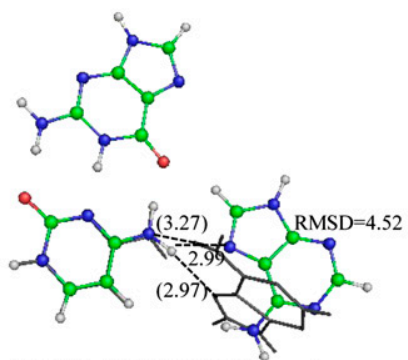

A9:C23:G12 (A:C H:H trans)

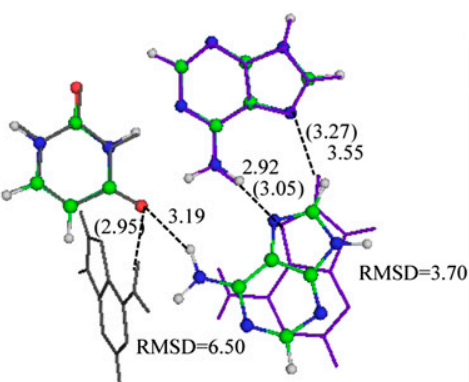

A9:U23:A12 (A:U(I) H:H trans and $A: A H: H$ cis)

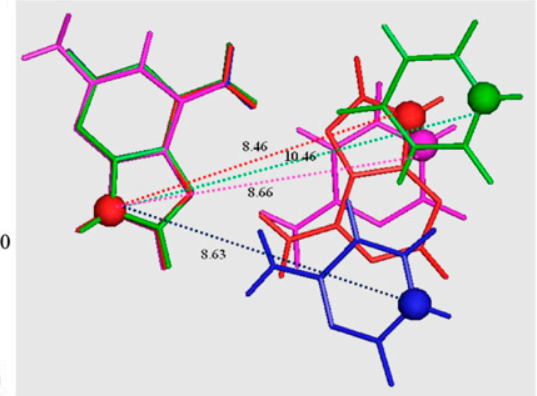

FIGURE 3. The upper four figures show the superposition, with respect to base 23/523, of gas phase optimized $\mathrm{H}: \mathrm{H}$ base-pair geometries (gray sticks) upon corresponding optimized geometries in 9:23:12 triplet contexts in tRNA structures (PDB ids in Table 5). The donoracceptor distances (in angstroms) are given for both isolated optimized geometries (within parentheses) as well as for geometries of $\mathrm{H}: \mathrm{H}$ base pairs in triplets (without parentheses). For the A9:U23:A12 triplet (bottom left), the uracil of the isolated A:U(I) H:H trans base pair (gray sticks) is superposed on $\mathrm{U} 23$ of the triplet, whereas the adenine of A:A H:H cis pair (blue sticks) is superposed on A12 of the triplet. In the last figure (bottom right), the 9:23/509:523 H:H combinations for the triplets G509:C523:C512, A9:C23:G12, A9:A23:U12, and A9:U23:A12 (depicted as purple, blue, red, and green sticks, respectively) are superposed with respect to bases 9/509 and the corresponding $\mathrm{Cl}^{\prime}-\mathrm{Cl}^{\prime}$ distances are given in Angstroms. Note the relatively larger $\mathrm{Cl}^{\prime}-\mathrm{Cl}^{\prime}$ distance for the A9:U23 combination.

2. To understand the perturbation in $\mathrm{H}: \mathrm{H}$ interaction in the presence of the third base of the triplet or quartet and to analyze whether the relatively less stable $\mathrm{H}: \mathrm{H}$ pattern is stabilized in the presence of the third base.

On the basis of deviation in optimized $\mathrm{H}: \mathrm{H}$ trans base-pair geometry upon triplet/quartet formation (measured in terms of RMSD between base-pair geometries in its isolated form and in the triplet structure), we find that all three triplets and two quartets involving A:A $\mathrm{H}: \mathrm{H}$ trans base pairs (Systems 2-5, 8) (Table 5) undergo very little deviation (maximum RMSD = $0.3 \AA$ ) upon triplet formation (Figs. 2,
3). This deviation is caused by attainment of the relatively planar geometry of the A:A trans base pair upon triplet or quartet formation, compared to its isolated energy-minimized geometry (discussed below in "Planarity of A:A trans base pairs in the presence of tertiary and phosphate interactions"). Small RMSDs have also been observed for the $\mathrm{H}: \mathrm{H}$ trans geometry of the A:U(II) pair present in the A:U:G (System 6) triplet and the $\mathrm{G}: \mathrm{C}(\mathrm{I})$ pair present in the $\mathrm{C}: \mathrm{G}: \mathrm{C}$ and $\mathrm{G}: \mathrm{C}: \mathrm{G}$ triplets (Systems 11 and 12, respectively). It may be noted that the $\mathrm{H}: \mathrm{H}$ base pairs present in all the triplets discussed above [i.e., A:A, A:U(II), and G:C(I)] are stable in the gas phase as well as the solvent phase and undergo little deviation compared to their crystal geometries. Similarly, the C:G:C triplet (System 6) involving the G:C(II) pair undergoes medium deformation (2.02 $\AA$ ) upon triplet formation. Smaller RMSD values indicate that these base pairs do not require high deformation energy for triplet formation and have an inherent propensity to associate with the third base to form higher-order structures.

On the other hand, three triplets (Systems 1, 9, and 10) involving A:G cis, A:C trans, and $\mathrm{A}: \mathrm{U}(\mathrm{I})$ trans base pairs, respectively, undergo high RMSD (Table 3) upon optimization. It is interesting to note that these three base pairs also undergo high deviation upon energy minimization of their isolated crystal geometries. In fact, isolated optimized geometries of A:C trans and A:U(I) trans are highly nonplanar (discussed above in "Classification of $\mathrm{H}: \mathrm{H}$ base pairs in terms of structural variability may be used to augment isostericity-basd classification"). However, upon triplet formation, these base pairs attain stable geometries, and the high deformation energy for triplet formation is compensated by interaction with the third base of the triplet. For example, in the optimized geometry of the A:G:C triplet (System 1), in order to form the triplet, the isolated optimized A:G cis base pair undergoes a deformation of $\sim 7 \mathrm{kcal} / \mathrm{mol}$. However, this deformation energy is compensated by the interaction of A1472 with both G2033 and C2037, which results in overall stabilization of the complete triplet motif. Thus, it appears that triplet formation results in attainment of planarity 
stabilization of the otherwise nonplanar and less stable $\mathrm{H}: \mathrm{H}$ base pairs.

From the above analysis, it can be concluded that some of the $\mathrm{H}: \mathrm{H}$ base pairs are inherently stable, while others get stabilized upon formation of higher-order structures. The formation of triplets and quartets appears to be profitable in terms of stabilization of otherwise unstable base-pairing patterns. Formation of such energetically favorable interaction patterns may also serve as nucleation sites for folding of native RNA structures.

Isostericity and conservation in the 9:12:23 tRNA tertiary interaction involving the A:A trans base pair

To understand the geometric origin of covariation in the 9:12:23 tRNA tertiary interaction involving $\mathrm{H}: \mathrm{H}$ base pairs at the 9:23 position, we calculated the glycosidic N-N distances of $\mathrm{H}: \mathrm{H}$ base pairs in optimized geometries of distinct triplet combinations (Systems 8-12) (Table 5) occurring at this position in different tRNA structures analyzed in our data set using isostericity principles. We found that $C: G$, $\mathrm{G}: \mathrm{C}, \mathrm{A}: \mathrm{C}$, and A:A base pairs occurring at the 9:23 position, grouped in the same isosteric subfamily by Leontis et al. (2002), have very similar N-N distances and are found to covary at the 9:23 position in different tRNAs. Thus, the base-pair isostericity nicely explains the covariation pattern for these base pairs. On the other hand, the A: $\mathrm{U} H: \mathrm{H}$ trans base pair, although less stable and nonisosteric with the above pairs (Leontis et al. 2002), is also found at the same position in the tRNA ${ }^{\text {Cys }}$ structure of E. coli (Fig. 3). Comparison of geometry of the A9:U23:A12 triplet containing the A9:U23 base pair with other covarying triplets reveals that this triplet also contains the A9:A12 H:H cis interaction, in addition to the A9: $\mathrm{U} 23 \mathrm{H}: \mathrm{H}$ trans interaction. It appears that the weak A9:U23 interaction is unable to hold the A9 in position. As a result, A12 slightly shifts toward the A9 base pair while retaining U23:A12 canonical geometry, and takes advantage of compatible donoracceptor combinations present on the Hoogsteen edge of A9 in order to acquire additional stabilization. This suggests that otherwise nonisosteric combinations can also be incorporated in homologous sequences by local changes in the geometry within the macromolecular structures.

\section{Planarity of A:A trans base pairs in the presence of tertiary and phosphate interactions}

It is observed that compared to isolated base pairs, A:A trans pairs in triplets show lower propeller twist values and possess planar geometries (Supplemental Table S1; Supplemental Material). Especially notable is the case of the A:A:U triplet, where adenine of the A:U canonical pair interacts with another adenine through $\mathrm{H}: \mathrm{H}$ trans pairing. In the optimized geometry of this triplet, the A:A pair is planar ( propeller twist $=0.88^{\circ}$ ), compared to the nonplanar iso- lated optimized geometry (propeller twist $=36.2^{\circ}$ ). The higher propeller twist in isolated optimized geometries may be due to partial $s p^{3}$ hybridization, and consequent pyramidalization, of amino nitrogen atoms of the adenines. Triplet formation, involving strong $\mathrm{W}: \mathrm{W}$ cis interaction with uracil, possibly results in greater $s p^{2}$ character of the amino group and makes the adenine base better suited for interactions. This explanation is in keeping with earlier observations regarding environmental dependence of the state of hybridization of primary amino groups of nucleobases (Šponer et al. 2001). It may be noted that the structural role of primary amino groups of base pairs in forming tertiary and neighboring interactions in crystal structures has earlier been discussed in the case of $A: G W: W$ cis base pairs (Šponer et al. 2003).

Atomic-resolution structures of the ribosomal subunits of the archaeon Haloarcula marismortui and bacteria E. coli and Deinococcus radiodurans suggest that many of the A:A $\mathrm{H}: \mathrm{H}$ trans interactions also involve base-phosphate interactions in addition to base-base interactions (Supplemental Material). The phosphate groups are observed to interact by forming one, two, three, or four hydrogen bonds with the A:A base pairs. In the case of single and two basephosphate hydrogen-bond interactions, the $\mathrm{C} 8-\mathrm{H}$ groups of either one or both the adenines interact with the phosphate oxygen atoms to form hydrogen bonds. On the other hand, in the case of three and four phosphate interactions, $\mathrm{C} 8-\mathrm{H}$ groups of both the adenines, as well as amino groups of either one or both the adenines, interact with phosphate oxygen atoms. A recent study has established that the $\mathrm{C} 8-\mathrm{H}$ as well as amino groups of adenines can interact with phosphate with significant binding energies (Zirbel et al. 2009). In order to understand the effect of such base-phosphate interactions on the structures of A:A $\mathrm{H}: \mathrm{H}$ trans base pairs, we optimized two models retaining the phosphate groups. The first geometry was optimized by taking the initial crystal geometry of A:A H:H trans where one of the phosphate groups was interacting with adenine, whereas the second geometry was optimized from the crystal structure where both phosphates were interacting with both adenines of the base pair. Since the phosphate groups are negatively charged, the anionic electrostatic interactions become dominant in the gas phase. However, in the aqueous cellular environment, these interactions are compensated in the presence of solvent. In order to mimic this effect and to make the calculations more meaningful, we included solvent effects during optimization using the COSMO method (Supplemental Fig. S1C,D). We find that interaction of phosphate with amino group interactions of both adenines results in reduction of buckle and significant gain of planarity of A:A H:H trans base pairs (Supplemental Material). This effect is similar to what was observed for this base pair upon triplet and quartet formation. This suggests that A:A trans base pairs, although intrinsically nonplanar, tend to use two different strategies to attain planarity in crystal 
structures through formation of tertiary interactions such as triplets or through base-phosphate interactions. These tendencies may also assist RNA folding by bringing nucleotides from different regions together to form triplets and also by constraining the backbone through base-phosphate interactions.

\section{Conclusion}

We carried out detailed structural and energetic analysis of $\mathrm{H}: \mathrm{H}$ families of RNA base pairs, which, as evidenced by their identification in known RNA crystal structures, play important roles in functional RNAs. For these base pairs, we have used advanced quantum chemical techniques to analyze their relative order of magnitude of interaction energies. In addition to investigating the isosteric features of these base pairs, we have used database analysis to report the detection of three previously unknown base pairs and have computed their hydrogen-bonding strengths. We have also used RMSD, as observed on optimization, along with base-pair parameter calculations, to analyze the geometric variability of base pairs.

A:A H:H trans is found to be the strongest and most frequently occurring base pair. This base pair serves in interdomain ribosomal contacts in the $50 \mathrm{~S}$ subunit and in $16 \mathrm{~S}$ rRNA. It is also a part of conserved tertiary interaction triplets in the D-stem in several tRNA structures. Although inherently nonplanar and propeller-twisted in its optimized geometry, this base pair was found to have a tendency to attain planar geometry in crystal structures using two different strategies. While one of these involves basephosphate interactions, in the second strategy the interaction of a third base induces planarity to the A:A H:H trans pair. The latter is even more pronounced when the third base interacts through the WC edge of one of the adenines.

We have also identified and characterized higher-order structures, including triplets and quartets, involving other $\mathrm{H}: \mathrm{H}$ base pairs. Our analysis shows that, apart from A:A trans, G:C and A:U trans base pairs have an inherent tendency to form base triplets, since they do not undergo significantly large deformation upon triplet formation. On the other hand, A:A and A:G cis base pairs compensate for the high deformation by an additional interaction with the third base of the triplet.

Overall, our studies show how a combined analysis of frequencies, interaction energies, stabilities, and occurrence contexts of these base pairs can augment isostericity-based classification and may lead to a better understanding of basepair covariation in unknown RNAs. Identification of previously unknown base-pair geometries from known crystal structures indicates the need to modify the existing popular algorithms for base-pair detection from RNA structures. The computed interaction energies may also be useful for implementing and modifying algorithms for RNA secondary structure prediction.

\section{MATERIALS AND METHODS}

\section{Identification and structural analysis of base pairs: Crystal structure database analysis}

We used a data set of selected high-resolution representative RNA crystal structures (PDB ids given in supporting information) from the Protein Data Bank (PDB). The recently developed BPFind (Das et al. 2006) program was used to (1) analyze the geometries of the base pairs present in these PDB files; (2) identify the base pairs and higher-order structures belonging to cis and trans $\mathrm{H}: \mathrm{H}$ families; and (3) analyze the occurrence contexts of base pairs belonging to these families. In addition, some of the structures were also taken from source PDBs listed by Leontis et al. (2002). We took the base pairs of these families from PDB files containing structures having higher resolution for our geometry optimizations and subsequent quantum chemical analysis.

\section{Model building}

The initial structural models of each of the base-pair combinations were built from selected examples from the PDB data set by extracting the coordinates of the corresponding nucleotides from PDB files using RASMOL (Sayle and Milner-White 1995) software. The PDB ids and base-pair ids of the examples of base pairs and higher-order structures used for computations are given in Tables 1 and 6, respectively. As the sugar O2' groups do not participate in $\mathrm{H}: \mathrm{H}$ base-pairing, we therefore replaced the ribose sugars attached to the bases with hydrogen atoms during model building. However, upon gas phase optimization of the isolated $\mathrm{G}: \mathrm{C}$ cis, G:G trans, and $\mathrm{U}: \mathrm{G}$ trans base pairs, it was found that the hydrogen atom that replaced the cytosine $\mathrm{Cl}^{\prime}$ in our models participates in interbase hydrogen bonds. To avoid this, the sugar $\mathrm{Cl}^{\prime}$ was replaced by a methyl group in these cases. For optimization of the U:G trans base pair in the gas phase, even the addition of a methyl group resulted in a weak interbase hydrogen bond. So, we retained the ribose sugar of uracil for gas phase optimization. However, as no such artifact was seen in solvent phase optimizations, this sugar was replaced by a hydrogen atom in this case. Thus G:C cis and G:G trans are represented as $\mathrm{G}: \mathrm{C}(\mathrm{m})$ cis and $\mathrm{G}: \mathrm{G}(\mathrm{m})$ trans, respectively, where " $\mathrm{m}$ " stands for the methyl group, and U:G trans is represented as U:G(s), where "s" stands for sugar, which is retained during computations. Models similar to those described above are well documented in the literature for studying RNA base pairs and are justified in the present context (Šponer et al. 2005a,b,c; Oliva et al. 2006; Bhattacharyya et al. 2007; Sharma et al. 2007, 2008a,b; Roy et al. 2008; Mládek et al. 2009).

\section{Computational details}

The Gaussian03 (Frisch et al. 2003) and GAMESS-US (Schmidt et al. 1993) suites of quantum chemical programs were used for all electronic structure calculations carried out here. The various keywords and options used for carrying out these calculations are given in the Supplemental Material. For each of the base-pair models prepared as described above, we followed the procedure described below.

\section{Optimization methods}

The geometries of the base pairs and higher-order structures obtained from RNA macromolecular crystal structures were fully 
optimized, free from any crystallographic constraints. Thus, in the complete neglect of forces present in the crystal environment, the relative arrangement of base pairs can undergo changes to different extents. Optimizations were carried out using density functional theory using the B3LYP functional (Becke 1993; Lee et al. 1988) and 6-31G $(\mathrm{d}, \mathrm{p})$ basis set of atomic orbitals with GAMESS-US software. The results for geometry optimizations at this level have been shown to correlate very well with the reference RIMP2/aug-cc-pVTZ structures and are sufficiently accurate to study base-pairing interactions in RNA molecules (Šponer et al. 2004). These geometries were used for subsequent gas phase interaction energy calculations.

\section{Solvent phase calculations}

In order to assess the bulk solvent screening of the electrostatic contribution to the base-pairing, we have repeated the optimizations at B3LYP/6-31G $(\mathrm{d}, \mathrm{p})$ using the Conductor-Like Polarizable Continuum Model (CPCM) (Barone and Cossi 1998; Cossi et al. 2003) with radii optimized for COSMO-RS (Klamt's radii) (Klamt et al. 1998) and the iterative solution (COSMO). The optimizations were carried out starting from the crystal geometries, using the "SCRF=( solvent=water $)$ " keyword with a dielectric constant of $\varepsilon=78.4$ (dielectric constant for pure water) (see http://www. gaussian.com/g_tech/g_ur/k_scrf.htm) to mimic the aqueous solvent. The Gaussian03 software was used for these calculations, where the United Atom Topological Model was used to define the atomic radii.

\section{Interaction energies}

We calculated the interaction energies for the optimized geometries at the MP2/aug-cc-pVDZ level using Gaussian03. In our recent studies on RNA base pairs, we have shown that the MP2/ aug-cc-pVDZ method underestimates the attraction only by $0.7-$ $1.7 \mathrm{kcal} / \mathrm{mol}$, when compared with the reference complete basis set (MP2/CBS) values, and is thus sufficient to understand the relative stability of base pairs (Mládek et al. 2009) and is sufficiently accurate for comparing the relative trends of interaction energies. The final interaction energy values were corrected for BSSE using the Standard Counterpoise Method (Boys and Bernardi 1970). It is known that the geometries of the individual bases in the optimized geometry of the base-pair complex are deformed with respect to their corresponding individually optimized geometries. Thus, the contribution of repulsive deformation energies must be added to the interaction energy values of optimized geometries. Therefore, we can define the total interaction energy $\left(E_{\text {tot }}\right)$ of the base pair as a measure for stabilization due to basepairing, as the difference between the electronic energies of the complex and the sum of those of the individual bases in their corresponding fully optimized geometries. For this, we can calculate $E_{\text {tot }}$ by adding a deformation energy correction term $\left(E_{\mathrm{def}}\right)$ to the $E_{\mathrm{int}}$ values. Thus,

$$
E_{\mathrm{tot}}=E_{\mathrm{int}}+E_{\mathrm{def}}
$$

Here $E_{\mathrm{def}}$ is the sum of deformation energies of individual bases calculated as the difference between the electronic energies of these bases in their respective complex and their corresponding individually optimized geometries computed using corresponding monomer basis sets.

$$
E_{\text {def }}=\left(E_{\mathrm{A}}-E_{\mathrm{A}}^{\circ}\right)+\left(E_{\mathrm{B}}-E_{\mathrm{B}}^{\circ}\right) .
$$

Here $E^{\circ}$ and $E$ are the energies of the bases corresponding to individually optimized geometry and those as components of a base pair, respectively.

\section{Interaction energy evaluation in the solvent phase}

The interaction energies in solution were calculated as the sum of gas phase interaction energies calculated for the COSMO optimized geometries $(E)$ and a solvation correction term (Mládek et al. 2009). Thus, the interaction energy in the solvent $\left(E_{\mathrm{sol}}\right)$ is defined as

$$
E_{\mathrm{sol}}=E+\left(E^{\mathrm{COSMO}}-E^{\mathrm{GAS} P H A S E}\right),
$$

where $E^{\mathrm{COSMO}}$ and $E^{\mathrm{GAS}}$ PHASE are the BSSE uncorrected interaction energy values in solvent phase and gas phase, respectively, evaluated for the solvent phase optimized geometries. $E_{\mathrm{sol}}$ was evaluated using Gaussian03. It may be noted that $E_{\text {sol }}$ cannot be directly correlated to free energies of binding in water, as many of the terms, including deformation energies, zero-point energy corrections, and entropic corrections of the solutes are not included. However, this method describes the perturbation of the electrostatic field of the solute molecules by the polar solvent, as well as the Coulombic interaction between the solute and solvent.

\section{Evaluation of variation in geometries on optimization}

Two methods were used to evaluate the relative variation in the geometries of each of the base pairs obtained from crystal structures, from gas phase calculations, and from COSMO calculations.

\section{RMSD}

In order to calculate the RMSD between two different geometries (i.e., the crystal geometry obtained from the macromolecular structure and the isolated optimized geometry) of the same basepair combination, first we superposed one of the bases from both the geometries and calculated the RMSD for the other base. Then the superposition is done for the second base, and the RMSD is calculated for the first base. The final RMSD values are taken as the average of the first base RMSD and the second base RMSD. It may be noted that superposition is performed only for nonhydrogen atoms of the bases. The algorithms for these superposition programs were described in our previous work (Bhattacharyya et al. 2007).

\section{Base-pair parameters}

In order to get a quantitative picture of change in base-pair geometry upon optimization of the crystal pair, we have also calculated the base-pair parameters (buckle, open, propeller, stagger, stretch, and shear) using the recently upgraded version of the NUPARM software, which takes into account the edge-specific base-pair system for parameter calculation of RNA base pairs (Mukherjee et al. 2006).

\section{SUPPLEMENTAL MATERIAL}

Supplemental material can be found at http://www.rnajournal.org. 


\section{ACKNOWLEDGMENTS}

This project was supported by the grant BT/PR5451/BID/07/111/ 2004 from the Department of Biotechnology (DBT), India. P.S. and S.S. acknowledge the Council for Scientific and Industrial Research, New Delhi, India, for senior research fellowships. The generous computational support from the Center for Development in Advanced Computing, Bangalore, is gratefully acknowledged.

Received September 7, 2009; accepted January 27, 2010.

\section{REFERENCES}

Barone V, Cossi M. 1998. Quantum calculation of molecular energies and energy gradients in solution by a conductor solvent model. J Phys Chem A 102: 1995-2001.

Becke AD. 1993. Density-functional thermochemistry. III. The role of exact exchange. J Chem Phys 98: 5648-5652.

Bhattacharyya D, Koripella SC, Mitra A, Rajendran VB, Sinha B. 2007. Theoretical analysis of noncanonical base pairing interactions in RNA molecules. J Biosci 32: 809-825.

Boys SF, Bernardi F. 1970. The calculation of small molecular interactions by the differences of separate total energies. Some procedures with reduced errors. Mol Phys 19: 553-566.

Brackett DM, Dieckmann T. 2006. Aptamer to ribozyme: The intrinsic catalytic potential of a small RNA. ChemBioChem 7: 839-843.

Brandl M, Meyer M, Sühnel J. 2000. Water-mediated base pairs in RNA: A quantum-chemical study. J Phys Chem A 104: 11177-11187.

Cerný J, Hobza P. 2007. Noncovalent interactions in biomacromolecules. Phys Chem Chem Phys 9: 5291-5303.

Cochrane JC, Storbel SA. 2008. Catalytic strategies of self-cleaving ribozymes. Acc Chem Res 41: 1027-1035.

Correll CC, Beneken JJ, Plantinga MJ, Lubbers M, Chan YL. 2003. The common and the distinctive features of the bulged-G motif based on a $1.04 \AA$ resolution RNA structure. Nucleic Acids Res 31: 68086818.

Cossi M, Rega N, Scalmani G, Barone V. 2003. Energies, structures and electronic properties of molecules in solution with the C-PCM solvation model. J Comput Chem 24: 669-681.

Das J, Mukherjee S, Mitra A, Bhattacharyya D. 2006. Noncanonical base pairs and higher order structures in nucleic acids: Crystal structure database analysis. J Biomol Struct Dyn 24: 149-161.

Frisch MJ, Trucks GW, Schelgel HB, Scuseria GE, Robb MA, Cheeseman JR, Montgomery JA Jr, Vreven T, Kudin KN, Burant JC, et al. 2003. Gaussian03, revision B.05. Gaussian, Inc., Pittsburgh, PA.

Hermann T, Westhof E. 1999. Non-Watson-Crick base pairs in RNAprotein recognition. Chem Biol 6: R335-R343.

Klamt A, Jonas V, Buerger T, Lohrenz JCW. 1998. Refinement and parametrization of COSMO-RS. J Phys Chem 102: 5074-5085.

Klein DJ, Schmeing TM, Moore PB, Steitz TA. 2001. The kink-turn: A new RNA secondary structure motif. EMBO J 20: 4214-4221.

Korostelev A, Trakhanov S, Laurberg M, Noller HF. 2006. Crystal structure of a $70 \mathrm{~S}$ ribosome-tRNA complex reveals functional interactions and rearrangements. Cell 126: 1065-1077.

Leclerc F, Karplus M. 2006. Two-metal-ion mechanism for hammerhead-ribozyme catalysis. J Phys Chem B 110: 3395-3409.

Lee C, Yang W, Parr RG. 1993. Development of the Colle-Salvetti correlation-energy formula into a functional of the electron density. Phys Rev B 37: 785-789.

Lemieux S, Major F. 2002. RNA canonical and noncanonical base pairing types: A recognition method and complete repertoire. Nucleic Acids Res 30: 4250-4263.

Leontis NB, Westhof E. 2001. Geometric nomenclature and classification of RNA base pairs. RNA 7: 499-512.

Leontis NB, Westhof E. 2003. Analysis of RNA motifs. Curr Opin Struct Biol 13: 300-308.
Leontis NB, Stombaugh J, Westhof E. 2002. The non-Watson-Crick base pairs and their associated isostericity matrices. Nucleic Acids Res 30: 3497-3531.

Lescoute A, Leontis NB, Massire C, Westhof E. 2005. Recurrent structural RNA motifs, isostericity matrices and sequence alignments. Nucleic Acids Res 33: 2395-2409.

McClain WH. 2006. Surprising contribution to aminoacylation and translation of non-Watson-Crick pairs in tRNA. Proc Natl Acad Sci 103: 4570-4575.

Mládek A, Sharma P, Mitra A, Bhattacharyya D, Šponer J, Šponer JE. 2009. Trans Hoogsteen/sugar edge base pairing in RNA. Structures, energies, and stabilities from quantum chemical calculations. J Phys Chem B 113: 1743-1755.

Mokdad A, Frenkel D. 2008. ISFOLD: Structure prediction of base pairs in nonhelical RNA motifs from isostericity signatures in their sequence alignments. J Biomol Struct Dyn 25: 467-472.

Mokdad A, Leontis NB. 2006. Ribostral: An RNA 3D alignment analyzer and viewer based on base-pair isostericities. Bioinformatics 22: 2168-2170.

Mukherjee S, Bansal M, Bhattacharyya D. 2006. Conformational specificity of noncanonical base pairs and higher order structures in nucleic acids: Crystal structure database analysis. J Comput Aided Mol Des 20: 629-645.

Müller J. 2008. Metal-ion-mediated base pairs in nucleic acids. Eur J Inorg Chem 2008: 3749-3763.

Nissen P, Ippolito JA, Ban N, Moore PB, Steitz TA. 2001. RNA tertiary interactions in the large ribosomal subunit: The A-minor motif. Proc Natl Acad Sci 98: 4899-4903.

Noller HF. 2005. RNA structure: Reading the ribosome. Science 309: $1508-1514$.

Oliva R, Cavallo L, Tramontano A. 2006. Accurate energies of hydrogen bonded nucleic acid base pairs and triplets in tRNA tertiary interactions. Nucleic Acids Res 34: 865-879.

Oliva R, Tramontano A, Cavallo L. 2007. $\mathrm{Mg}^{2+}$ binding and archaeosine modification stabilize the G15-C48 Levitt base pair in tRNAs. RNA 13: 1427-1436.

Olsen WK, Esguerra M, Xin Y, Lu X. 2009. New information content in RNA base pairing deduced from quantitative analysis of highresolution structures. Methods 47: 177-186.

Rázga F, Koča J, Šponer J, Leontis NB. 2005. Hinge-like motions in RNA kink-turns: The role of the second A-minor motif and nominally unpaired bases. Biophys J 88: 3466-3485.

Rodnina MV, Beringer M, Wintermeyer W. 2006. Mechanism of peptide bond formation on the ribosome. Q Rev Biophys 39: 203-225.

Roy A, Panigrahi S, Bhatatcharyya M, Bhattacharyya D. 2008. Structure, stability, and dynamics of canonical and noncanonical base pairs: Quantum chemical studies. J Phys Chem B 112: 3786-3796.

Sayle R, Milner-White EJ. 1995. RasMol: Biomolecular graphics for all. Trends Biochem Sci 20: 374-376.

Schmidt MW, Baldridge KK, Boatz JA, Elbert ST, Gordan MS, Jensen J, Koseky S, Matsunaga N, Nguyen KA, Su SJ, et al. 1993. General atomic and molecular electronic structure system. J Comput Chem 14: 1347-1363.

Serganov A, Keiper S, Malinina L, Tereshko V, Scripin E, Höbartner C, Polonskaia A, Phan AT, Wombacher R, Micura R, et al. 2005. Structural basis for Diels-Alder ribozyme-catalyzed carbon-carbon bond formation. Nat Struct Mol Biol 12: 218-224.

Sharma P, Mitra A, Sharma S, Singh H. 2007. Base pairing in RNA structures: A computational analysis of structural aspects and interaction energies. J Chem Sci 119: 525-531.

Sharma P, Mitra A, Sharma S, Singh H, Bhattacharyya D. 2008a. Quantum chemical studies of structures and binding in noncanonical RNA base pairs: The Trans Watson-Crick:WatsonCrick family. J Biomol Struct Dyn 25: 709-732.

Sharma P, Singh H, Mitra A. 2008b. Noncanonical base pairing in RNA: Topological and NBO analysis of Hoogsteen edge-sugar edge interactions. Lect Notes Comput Sci 5102: 379-386.

Sharma M, Bulusu G, Mitra A. 2009a. MD simulations of ligandbound and ligand-free aptamer: Molecular level insights into the 
binding and switching mechanism of the add A-riboswitch. RNA 15: $1673-1692$.

Sharma P, Sharma S, Chawla M, Mitra A. 2009b. Modeling the noncovalent interactions at the metabolite binding site in purine riboswitches. J Mol Model 15: 633-649.

Sharma P, Šponer JE, Šponer J, Sharma S, Bhattacharyya D, Mitra A. 2010. On the role of cis Hoogsteen:sugar edge family of base pairs in platforms and triplets-quantum chemical insights into RNA structural biology. J Phys Chem B 114: 3307-3320.

Špačková N, Šponer J. 2006. Molecular dynamics simulations of sarcin-ricin rRNA motif. Nucleic Acids Res 34: 697-708.

Šponer J, Leszczynski J, Hobza P. 2001. Electronic properties, hydrogen bonding, stacking, and cation-binding of DNA and RNA bases. Biopolymers 61: 3-31.

Šponer J, Mokdad A, Šponer JE, Špačková N, Leszczynski J, Leontis NB. 2003. Unique tertiary and neighbor interactions determine conservation patterns of cis Watson-Crick A/G base pairs. J Mol Biol 330: 967-978.

Šponer J, Jurecka P, Hobza P. 2004. Accurate interaction energies of hydrogen-bonded nucleic acid base pairs. J Am Chem Soc 126: 10142-10151.

Šponer JE, Leszczynski J, Sychrovský V, Šponer J. 2005a. Sugar edge/ sugar edge base pairs in RNA: Stabilities and structures from quantum chemical calculations. J Phys Chem B 109: 18680-18689.

Šponer JE, Špačková N, Leszczynski J, Sponer J. 2005b. Principles of RNA base pairing: Structures and energies of the trans WatsonCrick/sugar edge base pairs. J Phys Chem B 109: 11399-11410.
Šponer JE, Špačková N, Kulhánek P, Leszczynski J, Šponer J. 2005c. Non-Watson-Crick base pairing in RNA. Quantum chemical analysis of the cis Watson-Crick/sugar edge base-pair family. J Phys Chem B 109: 2292-2301.

Srinivasan AR, Sauers RR, Fenley MO, Boschitsch AH, Matsumoto A, Colasanti AV, Olsen WK. 2009. Properties of the nucleic-acid bases in free and Watson-Crick hydrogen-bonded states: Computational insights into the sequence-dependent features of doublehelical DNA. Biophys Rev 1: 13-20.

Steitz TA, Moore PB. 2003. RNA, the first macromolecular catalyst: The ribosome is a ribozyme. Trends Biochem Sci 28: 411-418.

Stombaugh J, Zirbel CL, Westhof E, Leontis NB. 2009. Frequency and isostericity of RNA base pairs. Nucleic Acids Res 37: 2294-2312.

Westhof E, Fritsch V. 2000. RNA folding: Beyond Watson-Crick pairs. Structure 8: R55-R65.

Yang H, Jossinet F, Leontis N, Chen L, Westbrook J, Berman H, Westhof E. 2003. Tools for the automatic identification and classification of RNA base pairs. Nucleic Acids Res 31: 34503460.

Zhong X, Leontis N, Qian S, Itaya A, Qi Y, Boris-Lawrie K, Ding B. 2006. Tertiary structural and functional analyses of a viroid RNA motif by isostericity matrix and mutagenesis reveal its essential role in replication. J Virol 80: 8566-8581.

Zirbel CL, Šponer JE, Šponer J, Stombaugh J, Leontis NB. 2009. Classification and energetics of the base-phosphate interactions in RNA. Nucleic Acids Res 37: 4898-4918. 

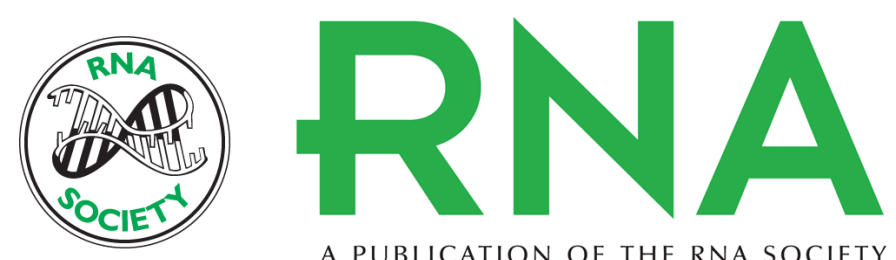

A PUBLICATION OF THE RNA SOCIETY

\section{On the role of Hoogsteen:Hoogsteen interactions in RNA: Ab initio investigations of structures and energies}

Purshotam Sharma, Mohit Chawla, Sitansh Sharma, et al.

RNA 2010 16: 942-957 originally published online March 30, 2010

Access the most recent version at doi:10.1261/rna.1919010

Supplemental
Material http://rnajournal.cshlp.org/content/suppl/2010/03/02/rna.1919010.DC1

References This article cites 59 articles, 8 of which can be accessed free at: http://rnajournal.cshlp.org/content/16/5/942.full.html\#ref-list-1

License

Email Alerting Receive free email alerts when new articles cite this article - sign up in the box at the Service top right corner of the article or click here. 